Review

\title{
Iridium-containing water-oxidation catalysts in acidic electrolyte
}

\author{
Yipu Liu a , Xiao Liang a , Hui Chen a, Ruiqin Gao a,b , Lei Shi a, Lan Yang a, Xiaoxin Zou a,* \\ a State Key Laboratory of Inorganic Synthesis and Preparative Chemistry, College of Chemistry, Jilin University, Changchun 130012, Jilin, China \\ b School of Biological and Chemical Engineering, NingboTech University, Ningbo 315100, Zhejiang, China
}

\section{A R T I C L E I N F O}

\section{Article history:}

Received 27 August 2020

Accepted 13 October 2020

Available online 5 March 2021

\section{Keywords:}

Electrocatalysis

Oxygen evolution reaction

Water splitting

Iridium

Proton exchange membrane

electrolyzer

\begin{abstract}
A B S T R A C T
With the goal of constructing a carbon-free energy cycle, proton-exchange membrane (PEM) water electrolysis is a promising technology that can be integrated effectively with renewable energy resources to produce high-purity hydrogen. $\mathrm{IrO}_{2}$, as a commercial electrocatalyst for the anode side of a PEM water electrolyzer, can both overcome the high corrosion conditions and exhibit efficient catalytic performance. However, the high consumption of Ir species cannot meet the sustainable development and economic requirements of this technology. Accordingly, it is necessary to understand the OER catalytic mechanisms for Ir species, further designing new types of low-iridium catalysts with high activity and stability to replace $\mathrm{IrO}_{2}$. In this review, we first summarize the related catalytic mechanisms of the acidic oxygen evolution reaction (OER), and then provide general methods for measuring the catalytic performance of materials. Second, we present the structural evolution results of crystalline $\mathrm{IrO}_{2}$ and amorphous $\mathrm{IrO}_{x}$ using in situ characterization techniques under catalytic conditions to understand the common catalytic characteristics of the materials and the possible factors affecting the structural evolution characteristics. Furthermore, we focus on three types of common low-iridium catalysts, including heteroatom-doped $\mathrm{IrO}_{2}\left(\mathrm{IrO}_{x}\right)$-based catalysts, perovskite-type iridium-based catalysts, and pyrochlore-type iridium-based catalysts, and try to correlate the structural features with the intrinsic catalytic performance of materials. Finally, at the end of the review, we present the unresolved problems and challenges in this field in an attempt to develop effective strategies to further balance the catalytic activity and stability of materials under acidic OER catalytic conditions.
\end{abstract}

(C) 2021, Dalian Institute of Chemical Physics, Chinese Academy of Sciences. Published by Elsevier B.V. All rights reserved.

\section{Introduction}

The booming energy demands of modern society require people to secure energy resources more wisely and widely [1]. Due to the unsustainable nature of fossil fuels, the dominant position of the global energy system needs to be substituted by renewable energy (e.g., solar, wind, and water power) step by step without hassle [2,3]. The mature strategy to utilize renewable energy is its direct transformation into electricity by photovoltaic modules, wind turbines, or hydropower dams $[1,4]$. In view of the intermittency of renewable sources, advanced energy-conversion and -storage solutions are urgently needed to achieve more convenient usage of this energy at any desired time [1,5-7]. Correspondingly, appropriate energy carriers should be carefully selected to empower the new integrated energy system. Hydrogen is the most promising candidate, owing to its high energy density and carbon-free features [8-11]. Fig. 1 displays an integrated energy system driven by

\footnotetext{
* Corresponding author. Tel/Fax: +86-431-85168221; E-mail: xxzou@jlu.edu.cn

This work was supported by the National Natural Science Foundation of China (21922507, 21771079, 22005116, 21621001), the Fok Ying Tung Education Foundation (161011), the International Postdoctoral Exchange Fellowship Program (20190054), and the 111 Project (B17020). DOI: 10.1016/S1872-2067(20)63722-6 | http://www.sciencedirect.com/journal/chinese-journal-of-catalysis | Chin. J. Catal., Vol. 42, No. 7, July 2021
} 
renewable energy using hydrogen as the energy carrier. In this energy system, fossil fuels are not involved. Renewable energy is first gathered to produce electricity, which can be used for hydrogen production by using water electrolyzers [10,12]. The resulting hydrogen can then be stored, applied in industry, and transported as a kind of fuel. In addition, the resulting hydrogen can also actuate fuel cells to generate power for transportation and other energy-related applications.

A water electrolyzer is one of the core apparatuses that constitute the above future energy system. Related electrolysis technologies can be grouped into three main categories: the proton-exchange membrane (PEM) water electrolyzer, alkaline water electrolyzer (AWE), and solid oxide electrolyzer (SOE) $[13,14]$. Among these, PEM water electrolyzers and AWE are commercially available devices, whereas SOE is less developed and thus beyond further discussion. Currently, AWE is the most widely employed device at the industrial level for hydrogen production because of its cost-effective components, such as non-noble-metal catalysts. Compared with AWE, the PEM water electrolyzer exhibits higher proton conductivity, lower gas crossover, and higher efficiency owing to the use of a solid polymer membrane (commonly Nafion) as the electrolyte. PEM water electrolyzers also offer better system compactness and shorter start-up time [4]. These features, especially fast response times, make PEM water electrolyzers more suitably coupled with intermittent renewable energy sources.

In this regard, it is important to develop high-performance, long-lifetime PEM water electrolyzers with reasonable cost. However, this goal is greatly impeded by the strong acid environment of PEMs. This harsh corrosive condition limits the selection range of catalytic materials for the hydrogen evolution reaction (HER) and the oxygen evolution reaction (OER)-two half-reactions of water electrolysis that occur on the cathode and anode of the electrolyzer, respectively. Only noble metal-based catalytic materials (Pt for HER and Ir for OER) currently exhibit acceptable acidic resistance and catalytic activity for PEM water electrolyzers in commercial use. As illustrated in the center of Fig. 1, the main components of the

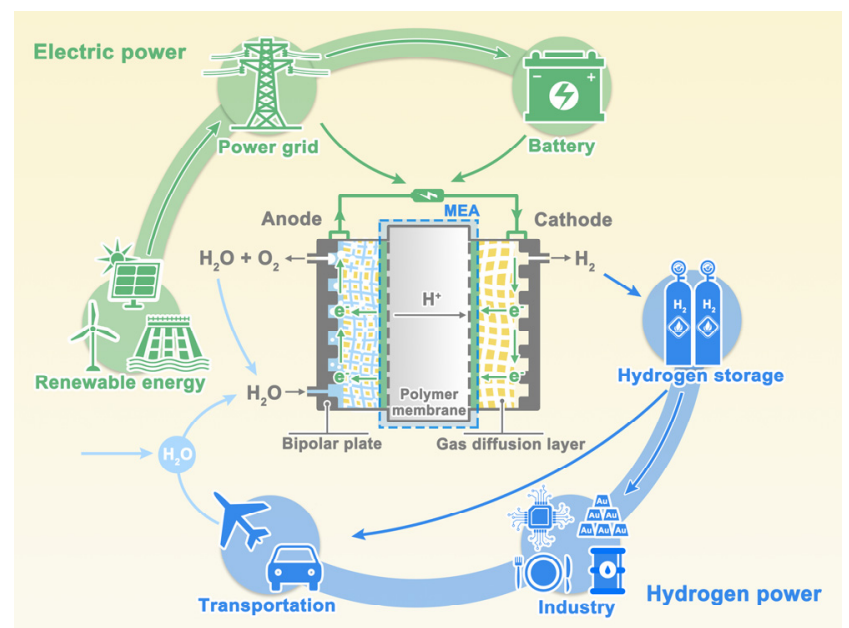

Fig. 1. Schematic illustration of the electrolyzer as a key part for constructing future hydrogen energy systems.
PEM water electrolyzer include the membrane electrode assembly (MEA), gas-diffusion layer (GDL), and bipolar plates (BPP) with flow channels [15]. The MEA serves as the core reaction region of the PEM water electrolyzer, and GDL together with BPP are responsible for transporting electrical current, water, and gaseous products (e.g., $\mathrm{H}_{2}$, and $\mathrm{O}_{2}$ ) [15]. The MEA is composed of a PEM and anode, cathode electrocatalysts, where the PEM functions as both electrolyte and diaphragm with good proton conductivity $\left(0.1 \pm 0.02 \mathrm{~S} \mathrm{~cm}^{-1}\right)$ to separate the anode and cathode parts of the electrolyzer (Fig. 1) [4]. Different methods can be used to fabricate the MEA, while the most commonly used method for researchers is directly coating the electrocatalyst slurry on the surface of the membrane, followed by hot-pressing treatment under a certain pressure [15]. Generally, a loading amount of approximately $0.025-0.3 \mathrm{mg} \mathrm{cm}^{-2}$ of Pt-based catalyst is sufficient to maintain high HER performance. However, an Ir-based catalyst needs at least a loading of $2 \mathrm{mg} \mathrm{cm}^{-2}$ to facilitate OER [4]. Moreover, the exchange current density of $\mathrm{H}^{+} / \mathrm{H}_{2}$ on a Pt-based catalyst is almost 1000 times larger than that of $\mathrm{H}_{2} \mathrm{O} / \mathrm{O}_{2}$ on Ir-based catalysts [16]. This also means that the sluggish OER is the bottleneck reaction for the PEM water electrolyzer, and dominantly determines the overall efficiency of water splitting.

Recently, various catalytic materials have been developed for acidic OER, mainly including precious-metal-based catalysts $(\mathrm{Ru}, \mathrm{Ir}, \mathrm{Pd}, \mathrm{Rh}$, and $\mathrm{Pt}$ species, etc.) and nonprecious-metal-based catalysts ( $\mathrm{Co}, \mathrm{Ni}, \mathrm{Fe}, \mathrm{Mn}$, and Mo species, etc.) [17-21]. However, most of the materials are restricted by a reverse relationship between catalytic activity and stability, and only Ir-based catalysts can somewhat balance the activity and stability as state-of-the-art OER catalysts for PEM water electrolyzers [22,23]. Ir is one of the least abundant elements in the Earth's crust, and the average mass fraction of Ir is approximately $0.001 \mathrm{ppm}$ in crustal rock [16]. In contrast, platinum (Pt, $0.005 \mathrm{ppm}$ ) is 5 times more abundant than Ir [24]. In addition, the production output of $\operatorname{Ir}(<9000 \mathrm{~kg} /$ year, in 2010) is approximately $4.5 \%$ of that of $\mathrm{Pt}$, and the price of $\mathrm{Ir}$ is also much higher than that of Pt (\$1485 for Ir vs. $\$ 895$ for Pt per troy ounce, in 2020) [19,25]. Based on these data, a back-of-the-envelope calculation can be performed. For a PEM water electrolyzer with an Ir loading of $2 \mathrm{mg} \mathrm{cm}^{-2}$ operating at $4 \mathrm{~W} \mathrm{~cm}^{-2}, 500 \mathrm{~kg}$ of $\mathrm{Ir}$ is required to reach gigawatt of power without considering the deactivation of the catalyst. It can be expected that a higher penetration of PEM water electrolyzers into the market would dramatically exacerbate both the demand and price of Ir. Thus, the high cost and low earth abundance are other key issues of Ir catalysts and cannot be simply overlooked [25].

In this review, we summarize recent research advances in Ir-containing electrocatalysts for OER under acidic conditions. We first introduce the possible catalytic mechanisms of Ir-containing electrocatalysts under OER, and then provide basic measurement methods for evaluating the catalytic properties of materials. Subsequently, we present some important structural characterization results for pure $\mathrm{IrO}_{2}$ and its relatives during the catalytic reaction. We then review some recent research efforts for designing low-iridium OER electrocatalysts, 
and further try to correlate these specific structural features with intrinsic catalytic properties. Finally, we provide some unsolved issues as future challenges at the end of this review.

\section{Catalytic mechanisms of OER in acidic media}

The OER on the anode in acidic media can be described by the following reaction (Eq. (1)) [26,27]:

$$
2 \mathrm{H}_{2} \mathrm{O}_{(\mathrm{l})} \rightarrow \mathrm{O}_{2(\mathrm{~g})}+4 \mathrm{H}^{+}+4 \mathrm{e}^{-} \quad E_{\left(\mathrm{O}_{2} / \mathrm{H}_{2} \mathrm{O}\right)}^{0}=1.23 \mathrm{~V} v \mathrm{~s} \text {. RHE (1) }
$$

$E_{\left(\mathrm{O}_{2} / \mathrm{H}_{2} \mathrm{O}\right)}^{0}$ is the standard anode potential for water oxidation into oxygen. However, a substantial overpotential is required to drive the OER because of its sluggish four-electron-involved reaction kinetics, constraining the efficiency of the overall water electrolysis process [28]. Considering the detailed catalytic steps of OER, multistep concerted and/or non-concerted proton-electron-transfer processes are possibly involved [29,30]. There are two kinds of catalytic mechanisms presented in the OER: (1) the adsorbate evolution mechanism (AEM) and (2) the lattice-oxygen oxidation mechanism (LOM). In AEM, the catalyst itself only provides appropriate adsorption sites, and the $\mathrm{O}_{2}$ gaseous product and all involved intermediates originate from the electrolyte. In LOM, the lattice oxygen atoms of the catalyst (mostly in the surface region) leave the lattice structure and directly participate in the formation of the dioxygen product during OER [21].

\subsection{Adsorbate evolution mechanism}

To determine the detailed schemes and internal influences under OER, various mechanistic steps have been proposed by different groups over the years [27]. In these proposed schemes, the OER always initializes from the discharge step of hydroxide ions at a catalytic active site (M) on the surface of the catalysts (Eq. (2)), further involving different intermediates $\left(\mathrm{O}^{*}, \mathrm{HO}^{*}, \mathrm{HOO}^{*}, \mathrm{O}_{2}^{*}, *\right.$ represents catalytic active sites) and various valence transitions of $\mathrm{M}$.

$$
\mathrm{M}+\mathrm{OH}^{-} \rightarrow \mathrm{M}-\mathrm{OH}+\mathrm{e}^{-}
$$

In fact, all of these schemes can be regarded as adsorbate evolution mechanisms, as surface lattice oxygen atoms do not serve as a part of the intermediate for the catalytic reaction. In fact, AEM always refers to a well-accepted scheme for investigating various catalysts (i.e., metal oxides/hydroxides) for OER under both acidic and alkaline conditions, and is also interpreted well with theoretical evaluation methods developed by the groups of Nörskov and Rossmeisl [31].

A typical AEM under acidic conditions is illustrated in Fig. 2(a). In the detailed mechanism steps, water molecules in the electrolyte first interact with the $\mathrm{M}$ site to form an $\mathrm{HO}^{*}$ intermediate (Eq. (3)). Then, the $\mathrm{HO}^{*}$ species deprotonates to produce M-O species by a concomitant one-electron transfer process (Eq. (4)). The M-O intermediate further reacts with water, forming adsorbed $\mathrm{HOO}^{*}$ at the $\mathrm{M}$ site (Eq. (5)), followed by the successive generation of $\mathrm{O}_{2}$ and the release of the $\mathrm{M}$ site (Eq. (6)).

$$
\begin{gathered}
\mathrm{M}+\mathrm{H}_{2} \mathrm{O} \rightarrow \mathrm{M}-\mathrm{OH}+\mathrm{H}^{+}+\mathrm{e}^{-} \\
\mathrm{M}-\mathrm{OH} \rightarrow \mathrm{M}-\mathrm{O}+\mathrm{H}^{+}+\mathrm{e}^{-}
\end{gathered}
$$
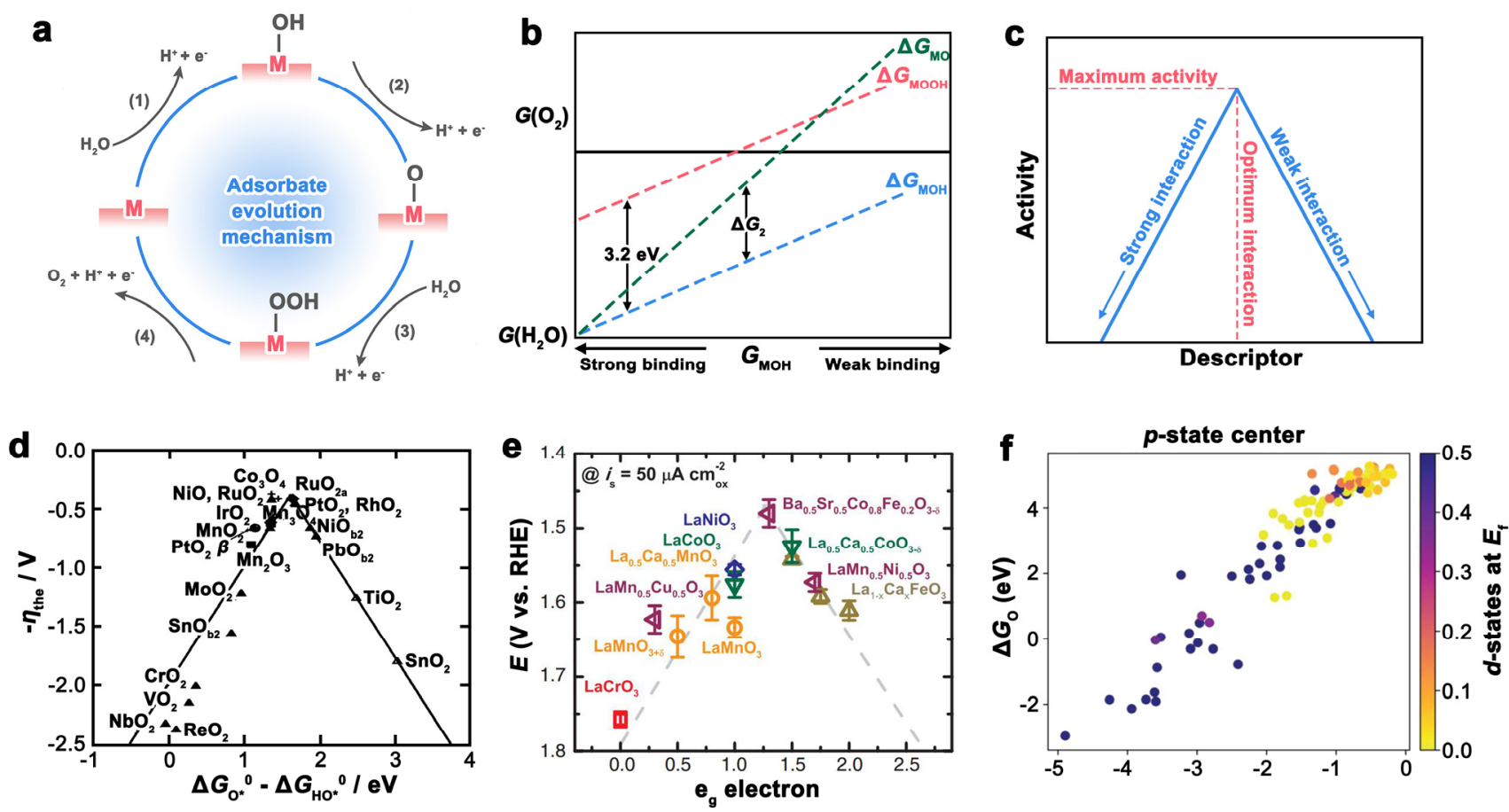

Fig. 2. Schematic illustration of (a) typical AEM scheme, (b) scaling relationship among M-OH, M-O and M-OOH, (c) a volcano plot using descriptor to represent the catalytic activity trend. (d) The volcano plot between catalytic activities and $\Delta G_{0}-\Delta G_{\text {он. }}$ Reproduced with permission [36]. Copyright 2011, Wiley-VCH. (e) The volcano plot between catalytic activities and eg electron. Reproduced with permission [38]. Copyright 2011, American Association for the Advancement of Science. (f) The relationship between $p$-state center and oxygen adsorption energy for cubic $\mathrm{ABO}_{3}$ oxides. Reproduced with permission. Copyright 2018, Royal Society of Chemistry [39]. 


$$
\begin{gathered}
\mathrm{M}-\mathrm{O}+\mathrm{H}_{2} \mathrm{O} \rightarrow \mathrm{M}-\mathrm{OOH}+\mathrm{H}^{+}+\mathrm{e}^{-} \\
\mathrm{M}-\mathrm{OOH} \rightarrow \mathrm{M}+\mathrm{O}_{2}+\mathrm{H}^{+}+\mathrm{e}^{-}
\end{gathered}
$$

Four concerted proton-electron-transfer processes are involved, indicating that the proposed mechanism should be independent of $\mathrm{pH}$ on the reversible hydrogen electrode (RHE) scale $[30,32]$. Due to the fact that the every separate reaction step cannot be evaluated clearly using experimental studies, the groups of Nörskov and Rossmeisl constructed an important computational standard hydrogen electrode model based on Density Functional Theory (DFT) to model the thermochemistry of electrochemical reactions [31]. This specific evaluation method for the OER is based on the as-stated mechanism scheme. More specifically, the chemical potential of $\left(\mathrm{H}^{+}+\mathrm{e}^{-}\right)$in solution is related to that of $1 / 2 \mathrm{H}_{2}$ in the gas phase by setting a standard hydrogen electrode (SHE) as the reference potential. This means that the reaction free energy of $1 / 2 \mathrm{H}_{2} \rightarrow \mathrm{H}^{+}+\mathrm{e}^{-}$is zero at standard conditions $\left(\mathrm{pH}=0, U=0, p_{\mathrm{H} 2}=1 \mathrm{bar}, T=298 \mathrm{~K}\right.$, where $U$ is the electrode potential relative to the SHE). Under such conditions, the free energy for each elementary step $\left(\Delta G_{1}\right.$, $\Delta G_{2}, \Delta G_{3}$, and $\left.\Delta G_{4}\right)$ can be calculated as Eqs. (7)-(10).

$$
\begin{aligned}
\Delta G_{1} & =E\left(\mathrm{HO}^{*}\right)-E\left(^{*}\right)-E_{\mathrm{H} 2 \mathrm{O}}+1 / 2 E_{\mathrm{H} 2}+(\Delta Z P E-T \Delta S)_{1}-\mathrm{e} U \\
\Delta G_{2} & =E\left(0^{*}\right)-E\left(\mathrm{HO}^{*}\right)+1 / 2 E_{\mathrm{H} 2}+(\Delta Z P E-T \Delta S)_{2}-\mathrm{e} U \\
\Delta G_{3} & =E\left(\mathrm{HOO}^{*}\right)-E\left(0^{*}\right)-E_{\mathrm{H} 20}+1 / 2 E_{\mathrm{H} 2}+(\Delta Z P E-T \Delta S)_{3}-\mathrm{e} U \\
\Delta G_{4} & =E\left({ }^{*}\right)-E\left(\mathrm{HOO}^{*}\right)+E_{02}+1 / 2 E_{\mathrm{H} 2}+(\Delta Z P E-T \Delta S)_{4}-\mathrm{e} U
\end{aligned}
$$

where the energies of $E\left(^{*}\right), E\left(\mathrm{HO}^{*}\right), E\left(\mathrm{HOO}^{*}\right), E_{\mathrm{H} 2}$, and $E_{\mathrm{H} 20}$ are calculated according to DFT calculations, and the differences in the zero-point energy ( $\triangle \mathrm{ZPE}$ ) and entropy $(T \Delta S)$ are obtained from the calculations of vibrational frequencies using DFT and the standard tables for gas molecules, respectively. Moreover, to avoid calculations of $\mathrm{O}_{2}$, which may not be described accurately using DFT, the free energy change of the total reaction $\left(2 \mathrm{H}_{2} \mathrm{O} \rightarrow 2 \mathrm{H}_{2}+\mathrm{O}_{2}\right)$ is fixed at $2.46 \mathrm{eV}$ per water molecule according to experimental value [31]. Accordingly, every $\Delta G$ for the above four elementary steps can be obtained, and the larger the $\Delta G$, the more energy should be consumed to make the step happen. This means that the step with the largest $\Delta G$ value in $\Delta G_{1-4}\left(\max \left[\Delta G_{1-4}\right]\right)$ is the last step to become downhill with the increased additional potential, and the corresponding step is regarded as the potential-determining step (PDS). The theoretical overpotential ( $\eta^{\text {OER }}$ can be calculated using Eq. (11).

$$
\eta^{\text {OER }}=\frac{\max [\Delta G 1-4]}{e}-1.23 \mathrm{~V}
$$

This potential is also termed the thermodynamic overpotential. At this potential, all thermodynamic barriers are removed and each substep in the reaction should be thermodynamically neutral or downhill [27]. Note that the theoretical overpotential $\eta^{\text {OER }}$ is a prediction of the thermodynamic limits of the OER, and it does not contain any electrokinetic terms. Thus, its value should not be directly comparable with the experimental result [33].

As classical models for OER, Rossmeisl et al. [34] investigated the theoretical electrocatalytic properties and adsorption behaviors of (110) surfaces of three rutile-type oxides $\mathrm{RuO}_{2}$, $\mathrm{IrO}_{2}$, and $\mathrm{TiO}_{2}$ ) according to the above methods. An activity trend of $\mathrm{RuO}_{2}>\mathrm{IrO}_{2}>>\mathrm{TiO}_{2}$ was observed under OER conditions. From the binding energy results, $\mathrm{RuO}_{2}$ binds oxygen a little too weakly $\left(\Delta E_{0^{*}}=2.66 \mathrm{eV}\right.$ ), leading to a relatively low overpotential of $0.37 \mathrm{~V}$. On the other hand, $\mathrm{IrO}_{2}$ binds $0^{*}$ rather too strongly with a binding energy of $1.66 \mathrm{eV}$, and the as-calculated overpotential is $0.56 \mathrm{~V}$, demonstrating the same trend as the experimental observation [35]. Due to the strong $\mathrm{O}^{*}$ adsorption of $\mathrm{IrO}_{2}$, the PDS of $\mathrm{IrO}_{2}$ is identified as the formation of $\mathrm{HOO}^{*}\left(\mathrm{O}^{*} \rightarrow \mathrm{HOO}^{*}\right)$, and it is rational to conclude that the catalytic activity of $\mathrm{IrO}_{2}$ can be enhanced by effective strategies that can reasonably weaken the adsorption of $0^{*}$ on the catalytic sites. In addition, the authors also found a universality of scaling relations among different intermediates, and this universality was further extended to rutile, perovskite, spinel, rock salt, and bixbyite oxides [28,36]. To be specific, as shown in Fig. 2(b), there is constant energy difference around 3.2 $( \pm 0.2)$ eV between $\Delta G_{\mathrm{HO}}$ and $\Delta G_{\mathrm{HOO}^{*}}$, and the slope of scaling relation between $\Delta G_{\mathrm{HO}^{*}}$ (or $\Delta G_{\mathrm{HOO}^{*}}$ ) and $\Delta G_{\mathrm{O}^{*}}$ is about $0.5-0.6$ [34]. The scaling relation between two intermediates $\mathrm{a}$ and $\mathrm{b}$ can be further summarized using Eq. (12) [37]:

$$
\Delta G_{\mathrm{b}}=\mathrm{A}_{\mathrm{a}, \mathrm{b}} \Delta G_{\mathrm{a}}+\mathrm{B}_{\mathrm{a}, \mathrm{b}}
$$

where some of the slopes $A_{a, b}$ and the intercepts $B_{a, b}$ are assumed to be constant values for three 0-containing intermediates $\left(\mathrm{A}_{\mathrm{a}, \mathrm{b}}=1, \mathrm{~B}_{\mathrm{a}, \mathrm{b}}=3.2\right.$ for $\Delta G_{\mathrm{HO}^{*}}$ and $\Delta G_{\mathrm{HOO}^{*}}$, and $\mathrm{A}_{\mathrm{a}, \mathrm{b}}=0.5 .0 .6$ for $\Delta G_{\mathrm{HO}^{*}}$ and $\Delta G_{0^{*}}$ ). From Eq. (12), it can be concluded that if the values of $\Delta G_{0^{*}}$ and $\mathrm{B}_{\mathrm{a}, \mathrm{b}}$ for $\Delta G_{\mathrm{O}^{*}}$ and $G_{\mathrm{HO}^{*}}$ of one specific catalyst can be calculated, the values of $\Delta G_{\mathrm{HO}}$ and $\Delta G_{\mathrm{HOO}}$ can be predicted to some extent according to the scaling relation.

When seeking the internal origin of the scaling relation, it has been shown that the slope of these scaling relations correlates with the number of bonds to the adsorptive site for every intermediate [27]. Both $\mathrm{OH}^{*}$ and $\mathrm{OOH}^{*}$ bond $\mathrm{M}$ with a single bond, and the slope of the scaling relation is 1 . In another case, M-O connects the surface with two bonds, and the corresponding slopes between $\mathrm{OH}^{*}$ and $\mathrm{O}^{*}$ or between $\mathrm{OOH}^{*}$ and $\mathrm{O}^{*}$ are around 0.5 . The bonding patterns of intermediates actually depend on the electron-counting rule (i.e., the octet rule). This demonstrates that these scaling relations originate from intermediates rather than catalytic active sites, further leading to the corresponding universality among various metals and oxides. Based on the universal limit of the scaling relation, it is difficult to design an ideal catalyst with minimal thermodynamic overpotential under the framework of AEM. The constant binding energy of $3.2 \mathrm{eV}$ between $\mathrm{M}-\mathrm{OH}$ and $\mathrm{M}-\mathrm{OOH}$ actually confines at least $0.37 \pm 0.10 \mathrm{~V}$ thermodynamic overpotential of OER, considering that every step should consume $1.23 \mathrm{eV}$ with the transfer of one electron and one proton at optimum [28]. This may be the reason why numerous reported OER catalysts exhibit an overpotential in the range of $0.3-0.4 \mathrm{~V}$, and the overpotentials cannot be further reduced easily [5]. Therefore, in the framework of AEM, how to break the scaling relationship is a crucial issue for the development of OER catalysts, and strategies that can change the slope $\mathrm{A}^{*}{ }_{0},{ }^{*} \mathrm{OH}$ (the relation between ${ }^{*} \mathrm{O}$ and ${ }^{*} \mathrm{OH}$ ) and/or the intercept $\mathrm{B}^{*} \mathrm{OH},{ }^{*} \mathrm{OOH}$ (the relation between ${ }^{*} \mathrm{OH}$ and ${ }^{*} \mathrm{OOH}$ ) should be explored to circumvent this internal issue.

Many recent research efforts have been made to find rational descriptors of OER-a single microscopic parameter to describe the catalytic activities of different electrode materials. A descriptor could be any internal property of the catalyst or 
catalyst-reactant interaction. Successful descriptors can always describe the interaction strength between key intermediates involving catalytic reaction and the catalytic active sites in the surface region [27]. According to such descriptors, a valcano plot can be obtained (Fig. 2(c)), and the maximum activity can be achieved at an optimum descriptor value with moderate interaction. Because of the scaling relation between $\mathrm{M}-\mathrm{O}, \mathrm{M}-\mathrm{OH}$, and $\mathrm{M}-\mathrm{OOH}$, it has been proven that both $\Delta G_{\mathrm{O}}$ and $\Delta G_{\mathrm{O}}-\Delta G_{\mathrm{OH}}$ can serve as appropriate descriptors for OER, representing the internal oxygen affinity of catalytic surfaces [31,36]. Fig. 2(d) displays a volcano plot, which shows the trend in the catalytic activity of various oxides as a function of $\Delta G_{\mathrm{O}}-\Delta G_{\mathrm{OH}}$ [36]. The optimum value of $\Delta G_{\mathrm{O}}-\Delta G_{\mathrm{OH}}$ is approximately 1.6 , which means that at such values, the catalysts bind the intermediates neither too weakly nor too strongly. Additionally, the PDS of the catalysts can also be concluded using such volcano plots through different 0 binding strengths. On surfaces that bind 0 strongly (left region of the valcano plot), the PDS is the formation of $\mathrm{M}-\mathrm{OOH}\left(\mathrm{O}^{*} \rightarrow \mathrm{HOO}^{*}\right)$. Correspondingly, when $\mathrm{O}$ binds the surfaces too weakly, PDS is the formation of $\mathrm{M}-\mathrm{OH}\left({ }^{*} \rightarrow\right.$ HO*, when $\Delta G_{1}>\Delta G_{2}$ in Eqs. (7) and (8)) or the oxidation of $\mathrm{M}-\mathrm{OH}\left(\mathrm{HO}^{*} \rightarrow \mathrm{O}^{*}\right.$, when $\Delta G_{2}>\Delta G_{1}$ ). This is determined by the relative free energy differences of $\Delta G_{1}$ and $\Delta G_{2}$.

In addition to direct intermediate adsorption interaction, several electronic structure-related descriptors have also been developed under the concepts of orbital occupancy and electron counting. Motivated by the successful application of the $d$-band theory to describe the catalytic activities of pure transition metals, Suntivich et al. [38] correlated the estimated $e_{g}$ occupancy of transition metal sites in perovskites with corresponding OER activities, obtaining a volcano-shaped dependence (Fig. 2(e)). The authors proposed that the eg filling of surface transition metal cations greatly influenced the binding energy of OER intermediates, as eg-orbitals in $\sigma$-bonding formed stronger overlaps with the oxygenated adsorbates. In addition, the Shao-Horn group also pointed out that the $02 p$ bands in perovskite oxides reflected the covalency character between metal sites and oxygen, and these values were further relevant to the relative activities of 0 -containing adsorbrates with catalytic active sites [40]. Moreover, the Vojvodic group screened ternary $\mathrm{ABO}_{3}$ perovskite oxides as OER catalysts using high-throughput computation and revealed the universal scaling relation between $\Delta G_{\mathrm{HOO}}$ and $\Delta G_{\mathrm{HO}}$ for perovskite-type catalysts [39]. By correlating the electronic structure of the perovskite surface with the corresponding free energy of oxygen adsorption, the authors reported that the center of the $p$-projected density of states (DOS) for surface oxygen atoms served as a more general parameter to reflect the adsorption behavior of $\mathrm{O}^{*}$ adsorbates on the B site (Fig. 2(f)). Additionally, the parameters evaluated from the $d$-band model (total $d$-state filling, $\mathrm{e}_{\mathrm{g}}$-state filling, and $\mathrm{t}_{2 \mathrm{~g}}$-state filling) were not appropriate to describe the bond energy when the $d$-states of the B site are completely filled or unfilled.

\subsection{Lattice-oxygen oxidation mechanism}

The LOM of OER has recently been developed to bypass the adsorption scaling relation involved in AEM. In fact, due to the enhancement of characterization techniques at the molecular level, some catalysts have revealed that at least some degree of lattice oxygen atoms participate during the OER, including $\mathrm{Ru}$-/Ir-based catalysts, perovskites with high metal-oxygen covalency, and some Co-based catalysts [41]. As a newly identified mechanism, the detailed scheme of LOM is not clear enough, and the internal origin of LOM is not fully understood.

Fig. 3(a) summarizes three previously reported possible reaction pathways for LOM. The main differences among the three pathways lie in the binding pattern between lattice oxygen and the as-formed intermediate. In pathway 1 , the HO* derived from the water molecule first interacts with metal adsorption site $\mathrm{M}$, followed by an oxidation process to form $0^{*}$. This process is similar to the initial step of the AEM. In the next step, the $0^{*}$ species directly reacts with lattice oxygen to produce a dioxygen species $\left(\mathrm{OO}^{*}\right)$, releasing the $\mathrm{O}_{2}$ product and leaving an oxygen vacancy on the catalyst surface. The oxygen vacancy might be refilled by the adsorption of $\mathrm{HO}^{*}$, and this restoration step prevents the structure of the catalyst from collapsing. In pathway 2 , the as-formed $\mathrm{HO}^{*}$ intermediate chooses the lattice-oxygen site as the initial adsorption site, rather than the metal site. This means that $\mathrm{HO}^{*}$ directly combines with lattice-oxygen to form HOO*. The HOO* species subsequently dissociates to generate $\mathrm{O}_{2}$ and $\mathrm{H}^{+}$. The lattice oxygen also partially contributes to the final $\mathrm{O}_{2}$ product. In pathway 3 , two lattice oxygen atoms may couple with each other under OER conditions (step 1-step 2), forming two oxygen vacancies simultaneously on the catalyst surface.

In the framework of LOM, some non-concerted proton-electron-transfer processes (e.g., direct 0-0 coupling step) may be involved in the OER. This is a noticeable difference between the LOM and AEM. The Shao-Horn group reported that LOM-involved perovskite catalysts (e.g., $\mathrm{La}_{0.5} \mathrm{Sr}_{0.5} \mathrm{CoO}_{3-\delta}$, $\mathrm{Pr}_{0.5} \mathrm{Ba}_{0.5} \mathrm{CoO}_{3-\delta}$, and $\mathrm{SrCoO}_{3-\delta}$ ) exhibited pH-dependent catalytic behavior for the OER [30]. This phenomenon implies that the redox activity of lattice oxygen might be associated with $\mathrm{pH}$ conditions, and the rate-determining step of these catalysts might be limited by the concentration of protons. Additionally because of the involvement of the direct 0-0 coupling step, LOM can fundamentally circumvent the scaling relation limitation of OER adsorbates. As a result, catalysts based on LOM potentially have lower reaction barriers and faster reaction kinetics than those based on AEM [19,21].

Isotope labeling methods using ${ }^{18} 0$ together with in situ mass spectrometry are a powerful characterization combination for splitting the contributions of AEM and LOM for a given catalytic material. Mayrhofer and coworkers synthesized crystalline $\operatorname{Ir}^{18} \mathrm{O}_{2}$ and hydrous $\operatorname{Ir}^{18} \mathrm{O}_{x}$ as model materials, and traced their atomic structural evolution and $\mathrm{O}_{2}$ product during OER. The authors found that crystalline $\operatorname{Ir}^{18} \mathrm{O}_{2}$ and amorphous $\operatorname{Ir}^{18} \mathrm{O}_{x}$ behave in different ways under catalytic conditions [42,44]. Atom probe tomography (APT) revealed that the $160 \mathrm{H}$ groups interacted with $\mathrm{Ir}^{18} \mathrm{O}_{2}$ only in the surface region, and online electrochemical mass spectrometry (OLEMS) analyses demonstrated that molecular oxygen was generated totally from $\mathrm{H}_{2}{ }^{16} \mathrm{O}$ rather than from lattice ${ }^{18} \mathrm{O}$. These results suggest that the OER 
a

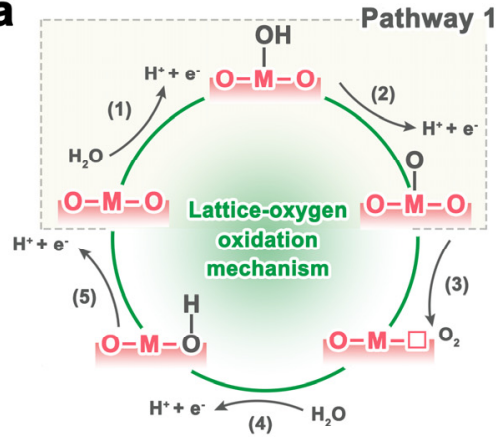

b

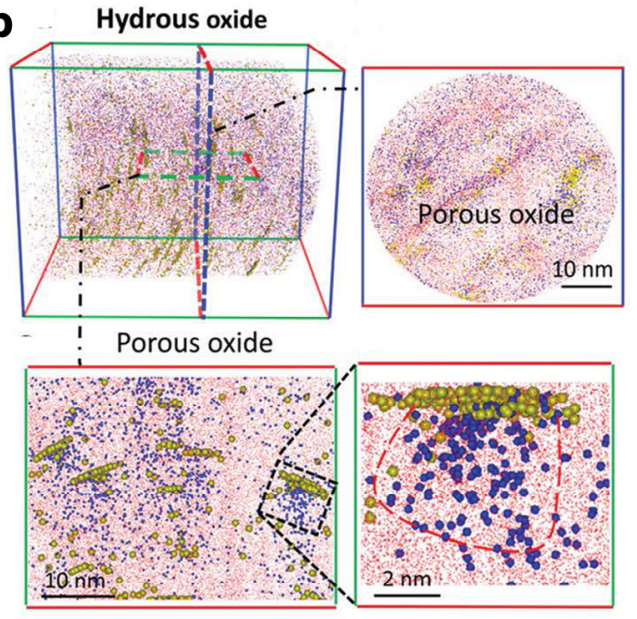

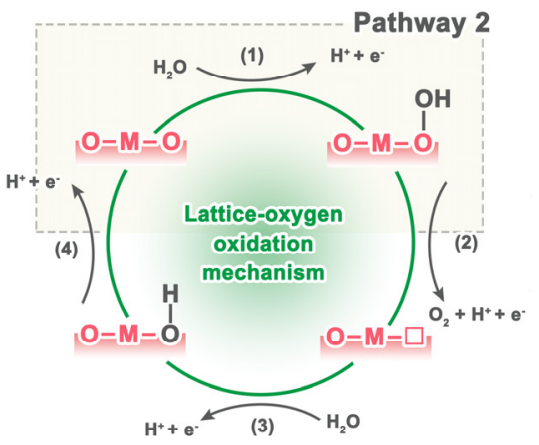

C
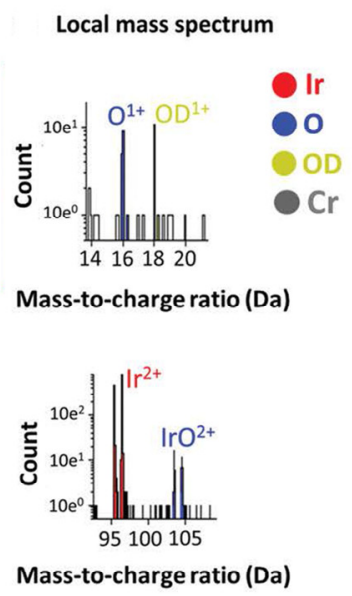

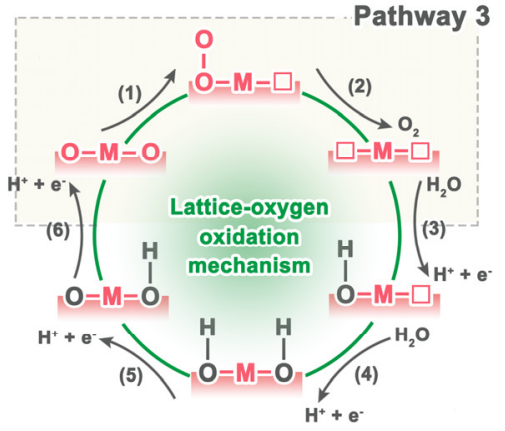

d
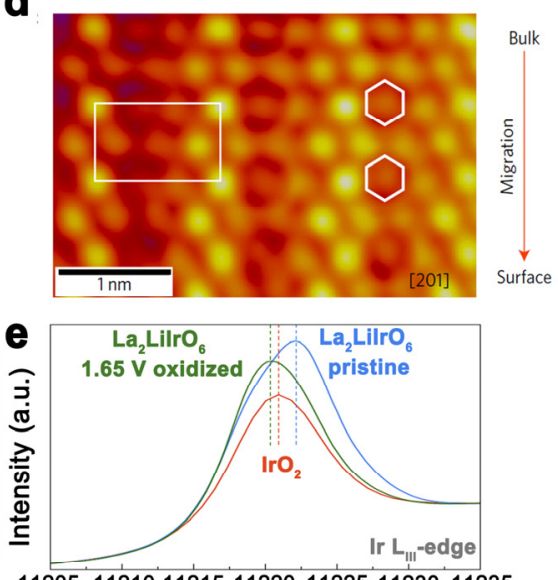

11205112101121511220112251123011235 Energy (eV)

Fig. 3. (a) Schematic illustration of three possible LOM schemes. (b) APT data of the near-surface region of hydrous Ir ${ }^{16} \mathrm{O}_{x}$. (c) Local mass spectrum of oxide cluster in (b). (b,c) Reproduced with permission [42]. Copyright 2019, Royal Society of Chemistry. (d) Colored HRTEM image of La $\mathrm{H}_{2}$ LiIrO 6 after $50 \mathrm{CV}$ measurements. (e) XAS spectra of pristine $\mathrm{La}_{2} \mathrm{LiIrO}_{6}, \mathrm{La}_{2} \mathrm{LiIrO}_{6}$ after oxidation and $\mathrm{IrO}_{2}$. (d,e) Reproduced with permission [43]. Copyright 2017, Nature Publishing Group.

in the presence of crystalline $\mathrm{IrO}_{2}$ followed the $\mathrm{AEM}$. In the case of amorphous $\operatorname{Ir}^{18} \mathrm{O}_{x}$, the high density of defects and the porous nature allowed the $160 \mathrm{H}$ groups to easily permeate into its loose structure, as demonstrated by the APT results (Figs. $3(\mathrm{~b}, \mathrm{c}))$. As for the oxygen products, ${ }^{16} \mathrm{O}^{16} \mathrm{O},{ }^{16} \mathrm{O}^{18} \mathrm{O}$, and ${ }^{18} \mathrm{O}^{18} \mathrm{O}$ were detected using OLEMS. The formation of ${ }^{18} 0^{18} \mathrm{O}$ also indicated that both oxygen atoms were derived from the oxide matrix. These results demonstrated that both AEM and LOM were involved in the $\operatorname{Ir}^{18} \mathrm{O}_{x}$-catalyzed OER.

In another example, Grimaud et al. [43] reported that $\mathrm{La}_{2} \mathrm{LiIrO}_{6}$ exhibited 50 times enhancement in OER activity compared with $\mathrm{IrO}_{2}$ at $\mathrm{pH}$ 1. Using differential electrochemical mass spectrometry (DEMS) in an organic solvent, the authors captured a surface oxygen loss process. In addition, the authors also observed the migration of bulk oxygen to the surface and the reduced oxidation state of the Ir species during the OER (Figs. 3(d,e)). [43]. In addition to the experimental results, the DFT results also showed that 0 species could be activated in the delithiated phase of $\mathrm{La}_{2} \mathrm{LiIIO}_{6}$, and some surface oxygen atoms exhibited an electrophilic nature. Based on the experimental and theoretical results, the authors postulated the involvement of LOM to explain the superior catalytic activity of $\mathrm{La}_{2} \mathrm{LiIrO}_{6}$ for the OER. The electrophilic surface oxygen was believed to be prone to interaction with water for the for- mation of $\mathrm{OOH}^{*}$ intermediates, followed by the simultaneous generation of molecular dioxygen and oxygen vacancies on the surface.

In contrast to AEM, the theoretical research on LOM is only at the initial stage, and the lattice oxygen participation during OER for various catalysts is still debated. The Alexandrov group compared the thermodynamic overpotential of AEM and LOM for rutile $\mathrm{RuO}_{2}$ and $\mathrm{IrO}_{2}$ catalysts using DFT calculations, further demonstrating the possible promotions of structural defects (vacancies and transition metal dopants) for the involvement of LOM [45]. The results showed that for perfect (110) and (211) surfaces of $\mathrm{RuO}_{2}$ and $\mathrm{IrO}_{2}$, AEM exhibited a much lower thermodynamic limit than LOM. This implied that perfect crystalline $\mathrm{RuO}_{2}$ and $\mathrm{IrO}_{2}$ followed a pathway of AEM, in agreement with the above experimental results. However, when structural defects were introduced into the surfaces of $\mathrm{RuO}_{2}$ and $\mathrm{IrO}_{2}$, the LOM pathway started to become competitive with a significantly reduced OER overpotential. In the case of $\mathrm{RuO}_{2}$, both surface vacancies and $\mathrm{Ni} / \mathrm{Co}$ dopants can switch the favorable OER mechanism from the AEM to the LOM, demonstrating that $\mathrm{RuO}_{2}$ is sensitive to structural defects. For $\mathrm{IrO}_{2}$, things become slightly different. Although the overpotential of LOM was also reduced in the presence of vacancies (from 2.40 to $0.33 \mathrm{~V}$ for $\mathrm{IrO}_{2}(110)$ ), $\mathrm{IrO}_{2}$ surfaces with low defect 
concentrations still preferred to follow AEM rather than LOM, demonstrating that LOM had a weaker destabilizing effect on the lattice of $\mathrm{IrO}_{2}$. These results demonstrate the reason why $\mathrm{IrO}_{2}$ exhibits a much better structural stability than $\mathrm{RuO}_{2}$ under OER electrochemical conditions. Additionally, by correlating the $02 p$-band center of the catalyst with OER overpotential, the authors suggested that this important parameter correlated well with the OER overpotential for both AEM and LOM, and the LOM became more competitive than the AEM when the $0-2 p$ band center of the catalyst moved closer to the Fermi level. In another theoretical work on perovskites, Yoo et al. $[46,47]$ also demonstrated the importance of the involvement of LOM on the catalytic activities of $\mathrm{ABO}_{3}$ perovskites, and the theoretical overpotentials of OER were much more explainable when the LOM was considered. The authors further reported that under $\mathrm{LOM}$, the lattice oxygen in $\mathrm{ABO}_{3}$ participated in the formation of reaction intermediates through the reversible formation of surface oxygen vacancies $\left(V_{0}\right)$.

It can be concluded that many structural properties of catalytic materials, including crystallinity, composition, defects, and crystal structure, can influence which reaction mechanism (AEM or LOM) is adopted under OER conditions [19], and there is also another reasonable possibility, which is that both AEM and LOM may occur on a given catalytic material simultaneously. Moreover, it should also be noted that the reversible oxygen vacancy refilling process of LOM seems to be closely associated with the structural stability of the catalyst. When the kinetics of refilling oxygen vacancies is slow, the restoration step of $\mathrm{HO}^{*}$ adsorption cannot catch up the generation rate of oxygen vacancies, and thereby structural degradation or cation dissolution may occur. Relevant experimental results also demonstrate that LOM-active perovskites generally undergo rapid surface amorphization and suffer from cation dissolution during OER operation, further leading to poor OER catalytic stability [40]. Therefore, besides catalytic activity, the structural stability of catalyst may also correlate with the involved mechanism during OER, and the corresponding surface structural evolution of catalyst should be carefully examined for both mechanism understanding and catalyst design.

\section{Experimental methods for evaluating catalytic performance of OER electrocatalysts}

Electrocatalysis is generally defined as a catalytic reaction occurring at the electrode-electrolyte interface, and the corresponding catalytic activity demonstrates the ability of an electrode surface or electrocatalyst material to facilitate the rate of the electrochemical process. For any research on electrochemical reactions, the core parameters should be the kinetic parameters that can describe the electro-transfer reactions under the purpose of fundamental investigation, together with the internal parameters that can represent the catalytic activity and stability of electrocatalysts from an application perspective. Current $(i)$ and potential $(V)$ are the most observable parameters for any electrochemical measurement. Generally, the current represents the rate of the interfacial reaction, and the potential can be regarded as the driving force for the electro- catalysis process. The current value is dependent on the applied potential from any given electrochemical process. The relationship between current and potential and some specific parameters for describing the intrinsic catalytic properties of catalysts are summarized in the following section.

\subsection{Experimental methods for evaluating catalytic activity}

\subsubsection{Overpotential}

Overpotential $(\eta)$ is one of the most effective parameters for evaluating the catalytic activity of materials. By performing a linear sweep voltammetry (LSV) measurement for a specific catalyst under a potential above $1.23 \mathrm{~V}$ vs. RHE (Fig. 4(a)), the polarization curve of the OER and the corresponding overpotential can be obtained. It should be noted that, for the accuracy of measurement, the scan rate of the LSV should be set as approximately $1 \mathrm{mV} / \mathrm{s}$, or a steady-state polarization curve should be conducted to eliminate the influence of the non-Faraday current. Additionally, due to the fact that different current values can be obtained by verifying the surface areas of the electrode, under a purpose of carrying out parallel comparisons for various catalysts, the measured catalytic current $(i$, $\mathrm{mA}$ ) during OER is generally normalized by the geometric area of the electrode $\left(A, \mathrm{~cm}^{2}\right)$ to get the geometric current density $\left(j_{\text {geo, }} \mathrm{mA} / \mathrm{cm}_{\text {geo }^{2}}\right)$, as shown in Eq. (13).

$$
j_{\text {geo }}=\frac{i}{A}
$$

The overpotential to achieve a geometric current density of $10 \mathrm{~mA} / \mathrm{cm}_{\text {geo }^{2}}$ is usually considered an important criterion for the assessment of catalytic activity with a lab-scale electrochemical testing system. This particular current density originates from the estimated current density generated by a solar water-splitting device with a $10 \%$ solar-to-fuel efficiency under an energy input of 1 sun illumination $[48,49]$. This parameter represents the apparent OER activity of the catalyst, which can also be estimated by the geometric current density at a given overpotential (e.g., $\eta=300 \mathrm{mV} v$ s. RHE). However because the geometric current density does not contain detailed information about the loading mass and/or surface area of the catalysts, this value fails to reflect the intrinsic activity of the nanostructured catalyst.

\subsubsection{Tafel slope and exchange current density}

Steady-state Tafel plot analysis is one of the most prevalent techniques for describing the electro-transfer process involved in electrocatalytic reactions. Generally, the relationship between the apparent catalytic current ( $i)$ and overpotential $(\eta)$ can be described mathematically using the Butler-Volmer equation (Eq. (14)).

$$
i=i_{0} \cdot\left\{\exp \left[\frac{\alpha_{\mathrm{a}} n F \eta}{R T}\right]-\exp \left[\frac{\alpha_{\mathrm{c}} n F \eta}{R T}\right]\right\}
$$

where $i_{0}$ is the exchange current representing the rate of forward and reverse reactions at the equilibrium potential [27], $T$ is the absolute temperature, $n$ is the total electron number involved in the reaction, $F$ is Faraday's constant, and $\mathrm{R}$ is the universal gas constant. $\alpha_{\mathrm{a}}$ and $\alpha_{\mathrm{c}}$ are the transfer coefficients for the anodic and cathodic reactions, respectively, and the sum of 

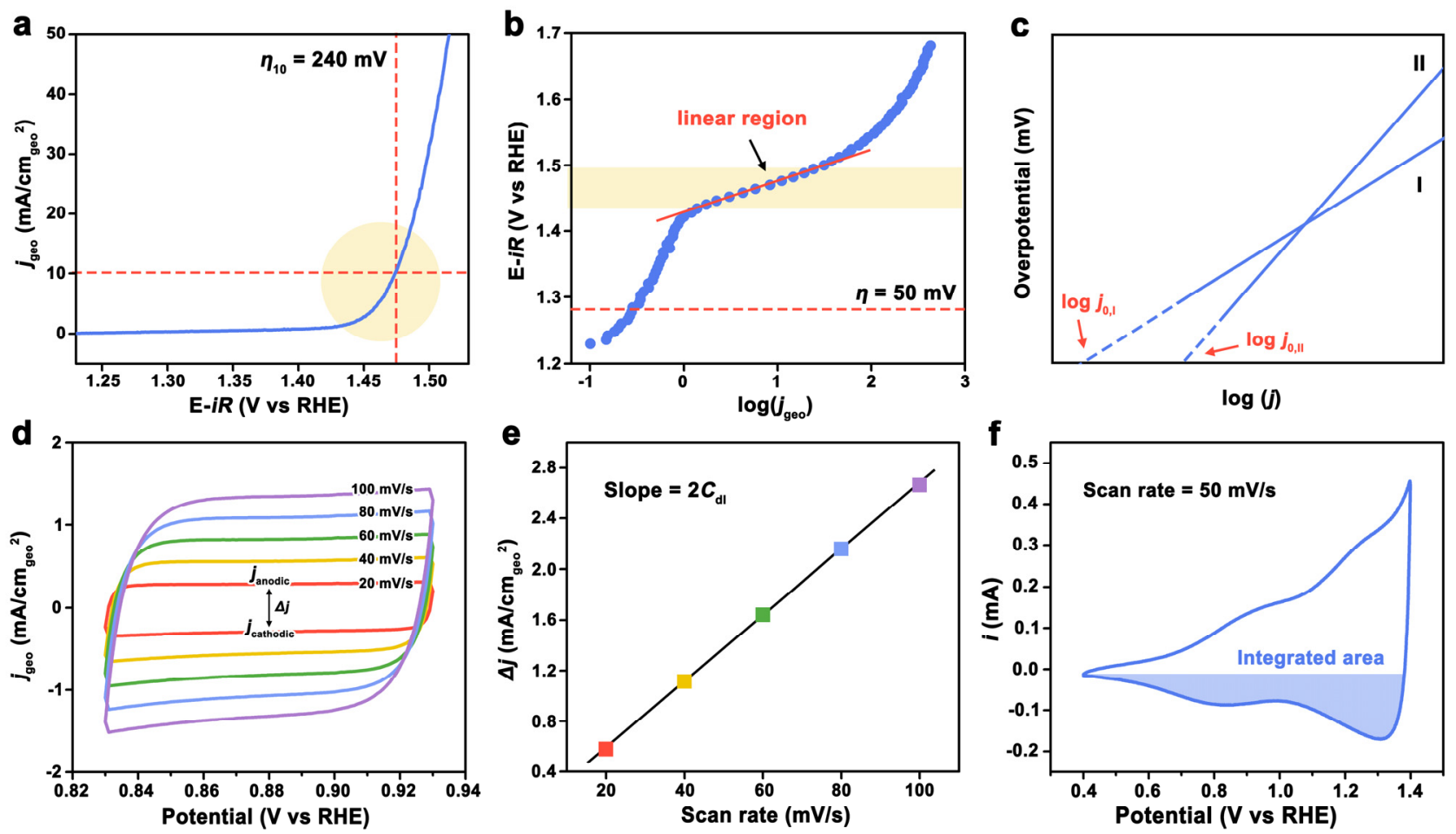

Fig. 4. (a) A polarization curve for OER. $\eta_{10}$ is the overpotential at $10 \mathrm{~mA} / \mathrm{cm}^{2}$. (b) A Tafel plot converted from (a). The red dashed line depicts the least potential deviation for determining the linear region. (c) Schematic diagrams of Tafel plot analysis for two specific catalysts. (d) CV plots with different scan rates under the non-Faradic range. (e) A linear trend conducted from the difference of $\Delta j$ against different scan rates. (f) $\mathrm{CV}$ plot of $\mathrm{SrZrO}_{3}-\mathrm{SrIrO}_{3}$ solid solution at a potential region of $0.4-1.4 \mathrm{~V}$ vs. RHE.

$\alpha_{\mathrm{a}}$ and $\alpha_{\mathrm{c}}$ is $1\left(\alpha_{\mathrm{a}}+\alpha_{\mathrm{c}}=1\right)$. From Eq. (14), the Butler-Volmer equation includes the contribution of both the anode reaction and the cathode reaction on one electrode surface. Note that in the potential range of OER, the anodic reaction dominates the total electrochemical reaction, and the cathode reactions can be ignored. Thus, under such conditions, the Butler-Volmer equation can be simplified to the Tafel equation (Eq. (15)).

$$
i=i_{0} \cdot \exp \left[\frac{\alpha_{\mathrm{a}} n F \eta}{R T}\right]
$$

By expressing the current in logarithmic form, the Tafel equation can be further depicted using Eqs. (16-18).

$$
\begin{aligned}
& \eta=a+b \log |i| \\
& a=\frac{2.303 R T}{\alpha_{\mathrm{a}} n F} \log \left|i_{0}\right| \\
& b=\frac{2.303 R T}{\alpha_{\mathrm{a}} n F}
\end{aligned}
$$

It is clear that there is a linear relationship between $\eta$ and $\log |i|$ predicted from Eq. (16) and the slope $b$ of the linear relation is well-known as the Tafel slope with a unit of millivolts per decade of current $(\mathrm{mV} / \mathrm{dec}) . a$ is the intercept of the linear relation, and the corresponding exchange current $i_{0}$ can be obtained by Eq. (17). Additionally, by normalizing the $i_{0}$ using geometric area of the electrode, the exchange current density (jo) can be obtained.

To correlate the Tafel equation with the actual experimental result, a general Tafel plot can be converted from the polarization curve by setting the $\log \mid j$ geo $\mid$ as the $x$ axis and the overpotential as the $y$ axis (Fig. 4(b)). The Tafel slope $b$ and exchange current density $j_{0}$ related to the catalytic reaction can be extracted by fitting the linear region in the Tafel plot. In addition because there may be more than one linear region in the Tafel plot, the potential range of the linear region should be chosen carefully and needs to satisfy two implicit requirements. (1) The potential range of the linear region in the Tafel plot should roughly correspond to the potential range where the current density starts to increase rapidly in the corresponding polarization curve [50], as illustrated by the light yellow region in Figs. 4(a,b). (2) The potential range of the linear region should deviate from the equilibrium potential for at least $\sim 50 \mathrm{mV}$ (Fig. 4(b)), considering that at this potential range, the contribution of the cathode reaction in the Butler-Volmer equation (Eq. (14)) can be eliminated to follow the establishing condition of the Tafel equation.

The Tafel slope is a multifaceted parameter that can provide rational interpretation for both catalytic activity and reaction mechanism. For basic catalytic activity evaluation, the Tafel slope can represent the rate of change of the current density with the electrode potential. From Eq. (16), a low Tafel slope indicates that the current density can increase rapidly with a small overpotential voltage change, demonstrating fast reaction kinetics. For fundamental mechanism characterization, the Tafel slope can demonstrate the rate-determining step (RDS) of the catalytic reaction. The RDS is actually highly correlated with the transfer coefficient $\alpha_{\mathrm{a}}$, which is experimentally estimable using Eq. (18) from the value of the Tafel slope. $\alpha_{\mathrm{a}}$ can be further deconstructed according to Eq. (19). 


$$
\alpha_{\mathrm{a}}=n_{\mathrm{f}} / v+n_{\mathrm{r}} \beta
$$

where $n_{\mathrm{f}}$ is the number of electrons transferred before the RDS, and $n_{\mathrm{r}}$ is the number of electrons participating during the RDS [27]. For the proton-electron-transfer process in OER, the value of $n_{\mathrm{r}}$ can be assumed to be 1. $v$ is the number of times for RDS in the overall reaction, and $\beta$ is the symmetry factor generally considered to be 0.5. By combining Eqs. (18) and (19), the RDS of the OER can be rationally evaluated. For example, if the first step of the OER (Eq. (3)) is RDS, the value of $\alpha$ a should be 0.5 , considering that $n_{\mathrm{f}}$ and $n_{\mathrm{r}}$ should be 0 and 1, respectively. Thus, the value of the Tafel slope can be inferred as $120 \mathrm{mV} / \mathrm{dec}$. This means that when the actual value of the Tafel slope is close to $\sim 120 \mathrm{mV} / \mathrm{dec}$, the RDS should be the formation of M-OH. Additionally, because the determination of RDS is a kinetic analysis of the catalytic reaction, it is important to distinguish the RDS from the concept of the PDS, as mentioned in Section 2.1. Note again that the PDS represents the predicted thermodynamic barrier for OER. The RDS as a kinetic concept includes the contribution of the activation barrier; therefore, the PDS and RDS should not necessarily be the same.

In addition to the Tafel slope, the exchange current density $j_{0}$ can also reflect the kinetics of the catalytic reaction. Generally, a large $j_{0}$ value indicates fast reaction kinetics and high catalytic performance. Thus, an effective catalyst generally exhibits a low Tafel slope with a high exchange current density. However, in the actual experimental case, a special situation exists where the Tafel slope $b$ does not correspond to the $j_{0}$ value, as illustrated in Fig. 4(c) [27]. Catalyst I exhibits a low Tafel slope with a low $j_{0}$ value, while catalyst II possesses a high $j_{0}$ value with a high Tafel value. More complicated explanations need to be conducted to describe these two catalysts. According to the physical interpretation of Eq. (14), $j_{0}$ may refer to the kinetics at the thermodynamic potential. It may not represent the reaction kinetics at a higher potential range, which is more meaningful for practical applications. Therefore, compared with the exchange current density, the Tafel slope is more important for determining the favorable catalytic properties. Catalyst I is more suitable for practical applications because it exhibits a higher current density at a lower overpotential than catalyst II.

\subsubsection{Mass activity, turnover frequency and specific activity}

As mentioned before, comparing the overpotential at a given geometric current density is a universal method for evaluating the catalytic performance. However, this geometric activity is largely dominated by the loading amount of the catalyst, and it cannot reflect the surface reaction behavior of the catalysis process, especially for nanostructured catalysts with roughened interfaces. Thus, other important parameters, including mass activity, turnover frequency, and specific activity, are summarized in this section, with the aim of providing a comprehensive activity evaluation for a particular catalyst.

The mass activity was obtained by normalizing the catalytic current to the loading mass of the catalysts or the total amount of active metal species in the catalysts at a given potential. This parameter correlates with the cost efficiency of the catalyst. A high mass activity demonstrates that a small amount of such catalyst would exhibit an efficient catalytic performance. Thus, considering the severe scarcity of Ir, iridium mass activity ( $j_{\mathrm{Ir}}$, $\mathrm{A} / \mathrm{g}_{\mathrm{Ir}}$ ) of iridium-based catalysts is an important parameter for evaluating iridium utilization in the catalyst. The corresponding equation is presented in Eq. (20).

$$
j_{\text {Ir }}=\frac{i}{m_{\text {loading }} \times \operatorname{Ir}(\mathrm{wt} \%)}
$$

where $\operatorname{Ir}(w t \%)$ is the mass fraction of iridium in catalyst and mloading (mg) represents the loading mass of catalyst. Note that the mass activity is not a parameter that represents the intrinsic activity of the catalyst. In view of the fact that the catalytic reaction generally occurs on the surface region of catalysts, a nanostructured catalyst with a high number of surface-active sites would exhibit higher mass activity than their bulk counterparts, but the two materials may possess similar intrinsic catalytic activity.

Turnover frequency (TOF) is defined as the number of products produced for a single catalytic site per unit of time at a given potential [51]. TOF is a reasonable parameter for describing the intrinsic activity of a catalyst. However, owing to the fact that it is difficult to obtain the real active site number of catalysts, the precise assessment of TOF values for heterogeneous electrocatalysts is still a challenge. Currently, there are three main methods for a compromise to evaluate TOF. The first involves converting the surface area of the catalysts to the number of active sites through a specific coefficient [52]. This coefficient defines the active site number per unit surface area, which is always determined according to the literature. The second is evaluating the number of active sites of the catalysts through cyclic voltammetry (CV) measurements. For materials with clear redox $\mathrm{CV}$ features, the corresponding coulombic charge $(\mathrm{Q})$ can be quantified by integrating the specified $\mathrm{CV}$ peak, further obtaining the number of possible participating atoms in the catalysts during the reaction. The last one assumes that all atoms in the catalyst serve as the active sites for the catalytic reaction, and the active site number is obtained by normalizing the loading amount of the catalyst with molecular weight. Unlike the previous two methods, the last method cannot reflect the intrinsic activity of the catalyst, whose value is essentially correlated with the mass activity of the catalyst.

The specific activity was estimated by normalizing the catalytic current with the surface area of the catalyst. As a more convenient alternative to TOF, it can reflect the intrinsic activity of the catalyst. Accordingly, this parameter can be used to demonstrate the internal differences among various catalysts, further revealing the fundamental structure-activity relationship of the catalysts. As a crucial variable for specific activity, the surface area of the catalyst refers to the real surface region that participates in the catalytic reaction. Thus, rational evaluation of specific activity calls for experimental approaches to determine the surface area of the catalyst. These methods can be roughly split into non-electrochemical methods and electrochemical methods.

For non-electrochemical methods, using adsorption and desorption measurements of probe gas molecules $\left(\mathrm{N}_{2}\right.$ for most frequently, or $\mathrm{CO}, \mathrm{O}_{2}, \mathrm{H}_{2}$, etc.) together with the corresponding Brunauer-Emmett-Teller (BET) adsorption isotherm studies is a method to evaluating the available surface area for 
nanostructured materials. The so-called BET-normalized specific activity $\left(j_{\mathrm{BET}}, \mathrm{mA} / \mathrm{cm}_{\mathrm{BET}^{2}}\right)$ can then be calculated using Eq. (21).

$$
j_{\mathrm{BET}}=\frac{i}{\mathrm{BET} \times 10 \times m_{\text {loading }}}
$$

where BET $\left(\mathrm{m}^{2} / \mathrm{g}\right)$ is the BET surface area. Owing to the universality of this measurement, this parameter is easily reproducible and provides a meaningful expression for intrinsic activity. However, it is difficult to monitor the structural changes of the catalyst during OER. In addition, the BET surface area of the material is not sufficiently reliable when the catalyst possesses a small surface area (e.g., $<20 \mathrm{~m}^{2} / \mathrm{g}$ ). In addition to the BET method, atomic force microscopy (AFM) and electron microscopy measurements (transmission electron microscopy and scanning electron microscopy) can also be used to evaluate the surface area of materials. AFM is capable of measuring the surface areas of thin-film electrodes, and it is appropriate to use electron microscopy measurements to evaluate materials with regular shapes [52].

As for electrochemical methods, the as-measured surface area of the catalyst should be more rational in terms of the electrochemical active surface area (ECSA, $\mathrm{cm}^{2}$ ). Then, the ECSA-normalized specific activity (jECSA, $\mathrm{mA} / \mathrm{cmECSA}^{2}$ ) can be obtained through Eq. (22).

$$
j_{\mathrm{ECSA}}=\frac{i}{\mathrm{ECSA}}
$$

To estimate ECSA, the double layer capacitance $\left(C_{\mathrm{dl}}\right.$, $\mathrm{mF} / \mathrm{cm}^{2}$ ) of the catalyst is the most universal indicator for extracting the surface area of the catalyst accessible to the electrolyte ions. Generally, a series of cyclic voltammetry (CV) measurements with different scan rates (e.g., 20, 40, 60, 80, and $100 \mathrm{mV} / \mathrm{s}$ ) are performed first in a potential window in the non-Faradic range (Fig. 4(d)). Then, a linear trend can be obtained by plotting the difference in the geometric current density $\left(\Delta j=j_{\text {anodic }}-j_{\text {cathodic }}\right)$ at the middle position of the potential range against the scan rate, as shown in Fig. 4(e). The half value of the resulting slope for the fitting line is the as-estimated $C_{\mathrm{dl}}$ of the catalyst. Finally, the ECSA can be obtained from $C_{\mathrm{dl}}$ according to Eq. (23)

$$
\mathrm{ECSA}=\frac{C_{\mathrm{dl}}}{C_{\mathrm{s}}} \times A
$$

where $C_{\mathrm{s}}\left(\mathrm{mF} / \mathrm{cm}^{2}\right)$ is the specific capacitance of the sample, which represents the capacitance of an atomically smooth planar surface of the material per unit area under identical electrolyte conditions [48]. Besides $C_{\mathrm{dl}}$ measurement, utilizing specific redox reactions occurring on the surface of the catalyst is another effective alternative to obtain the corresponding ECSA. The specified surface reactions include hydrogen underpotential deposition (HUPD), CO stripping reaction, underpotential deposition (UPD) of metal, surface redox reaction of the catalyst, and the coulombic charge $(Q, C)$ can be quantified from the corresponding redox region in characteristic CV peaks [52]. The ECSA can then be converted from $Q$ through a known specific charge, which is mostly determined by experimentally measured values or calculated results based on simplified models [52]. For example, Fig. 4(f) presents a CV plot that demonstrates the surface redox reaction of the $\mathrm{SrZrO}_{3}-\mathrm{SrIrO}_{3}$ solid solution [53]. A potential region of $0.4-1.4 \mathrm{~V} v$ s. RHE is set for this CV plot, assuming that only Ir species undergo in situ oxidation and reduction under such potential range. The value of $Q$ can then be extracted by integrating the backward reduction peak, reflecting the surface-active concentration of Ir sites. Additionally, rather than using specific charge to evaluate the corresponding ECSA, the Q-normalized specific activity (jQ, A/C) can be calculated by Eq. (24).

$$
j_{Q}=\frac{i}{Q}
$$

This is another parameter for obtaining comparable intrinsic activities. Both $j_{\mathrm{ECSA}}$ and $j_{Q}$ are sensitive for diagnosing the structural changes of catalysts during OER. However, they all suffer from poor reproducibility, considering that many practical factors such as catalyst mass loading, measurement configuration, electrode effect, and/or potential window range could influence the as-calculated value of ECSA and $Q$. Because of this limitation, a comparison of the intrinsic activity of various catalysts using $j_{\mathrm{ECSA}}$ or $j_{Q}$ is recommended to be carried out under the same testing conditions. The as-calculated $j_{\mathrm{ECSA}}$ or $j_{Q}$ from different reports could hardly be compared based on the above considerations, even for the same catalyst.

\subsubsection{Faradaic efficiency}

In addition to obtaining various parameters though the reaction current to evaluate the catalytic activity of materials, it is also important to determine if all the transferred electrons (charge) participate in the catalytic reaction of OER, or if some portions are consumed by other side reactions. Faradaic efficiency describes the efficiency of electron involvement for a specific reaction. The Faradaic efficiency can be obtained by calculating the ratio of the measured amount of evolved product (experimental value) to the expected amount of product based on Faraday's law (theoretical value). In the case of OER, the product is an as-generated $\mathrm{O}_{2}$ gas, and a $100 \%$ Faradaic efficiency means that $100 \%$ of the current output during electrolysis is derived from the OER without any side reactions. Additionally, there might be two main factors affecting the Faradaic efficiency of the OER. The first factor is derived from specific materials with reduced states (alloy materials, chalcogenides, phosphides, etc.) [5]. Due to the oxidation condition of OER, these catalytic species cannot remain stable, and some oxidation reactions together with irreversible valance increments would occur on the surface region of the materials. Accordingly, some of the electrons are consumed by these surface reactions. This would reduce the Faradaic efficiency of the OER, further generally accompanied by a transformation of the catalytic active phase. The other factor originates from some competitive redox couples in the electrolyte. For example, if there are certain amounts of chloride ions $\left(\mathrm{Cl}^{-}\right)$in the acidic electrolyte, the chlorine evolution reaction (CER) will theoretically start to occur when the applied potential reaches $1.36 \mathrm{~V}$ (equilibrium potential of CER) [54]. This means that the CER would tend to simultaneously occur at high current densities with OER, further influencing the calculated Faradaic efficiency of the OER.

\subsection{Experimental methods for evaluating catalytic stability}


In general, the electrocatalytic stability of a material is examined by a combination of many kinds of electrochemical measurements, such as chronoamperometry (CA), chronopotentiometry (CP), and LSV curves. However, these stability evaluation techniques are insensitive to the possible structural changes of materials. The catalytic stability of the OER catalyst may not necessarily correlate with its corresponding structural stability. In order to uncover possible structural variations of the catalysts, various characterization techniques should be used under in situ conditions, such as X-ray diffraction (XRD), X-ray photoelectron spectroscopy (XPS), X-ray absorption spectroscopy (XAS), energy-dispersive X-ray spectroscopy (EDS), inductively coupled plasma atomic emission spectroscopy (ICP-OES), Raman spectroscopy, and high-resolution transmission electron microscopy (HRTEM) [55].

Under acidic OER conditions, the inevitable dissolution of cations often occurs in all cases of various catalytic materials, and this is the core concern related to catalyst stability. In a notable example, the Markovic group investigated a series of monometallic oxides for acidic OER, and pointed out that the activity and stability trends of these oxides were actually reversed [56]. The activity followed a trend of $\mathrm{Os}>>\mathrm{Ru}>\mathrm{Ir}>\mathrm{Pt}$ $>>\mathrm{Au}$, while the catalytic stability increased in the order $\mathrm{Au}>>$ Pt > Ir > Ru >> Os (Fig. 5(a)). Ir oxide was identified to achieve promising activity with acceptable stability. Recently, different types of Ir-based materials have been developed for acidic OER, including amorphous and hydrous oxides [57-59], perovskites, pyrochlores, and hollandites with different chemical composi- tions and crystal structures. In fact, all of these Ir-based materials generally followed the reverse catalytic activity-structural stability relationship.

In order to better evaluate the catalytic properties of an OER catalyst, it is desirable to develop a common, simple, and comprehensive method to describe the activity-stability relation of an OER catalyst. Geiger et al. [60] investigated the dissolution behaviors of amorphous $\mathrm{IrO}_{x}$, crystalline $\mathrm{IrO}_{2}, \mathrm{SrIrO}_{3}$ perovskite, and $\mathrm{A}_{2} \mathrm{BIrO}_{6}(\mathrm{~A}=\mathrm{Ba}, \mathrm{Sr} ; \mathrm{B}=\mathrm{Nd}, \mathrm{Pr}, \mathrm{Y})$ double perovskite. Geiger et. al. [60] built an independent stability parameter, the so-called stability number (S-number), to define the intrinsic structural stability of the catalyst. The S-number can be calculated as the amount of evolved $\mathrm{O}_{2}$ divided by the amount of dissolved Ir, as shown in Eq. (25).

$$
\text { S-number }=\frac{n_{\mathrm{O}_{2} \text { (OER) }}}{n_{\text {Ir(dissolved) }}}
$$

where $n_{02(\mathrm{OER})}$ is the moles of produced $\mathrm{O}_{2}$, and $n_{\mathrm{Ir} \text { (dissolved) is the }}$ number of moles of leached Ir species. Based on this method, a promising electrocatalyst would exhibit a relatively high stability number, and the $\mathrm{S}$-number of $\mathrm{IrO}_{2}$ is evaluated to be approximately $1.0 \mathrm{E}+6$ to $1.0 \mathrm{E}+7$ (Fig. 5(b)). Moreover, the authors also proposed that the value of S-number was not influenced by the mass loading of the catalyst, surface area of the working electrode, and/or applied potential (Fig. 5(c)), demonstrating the potential universality of this specific parameter.

In another attempt, the Markovic group tried to quantify the activity-stability relationship of materials by proposing a parameter called the activity stability factor (ASF), which can be
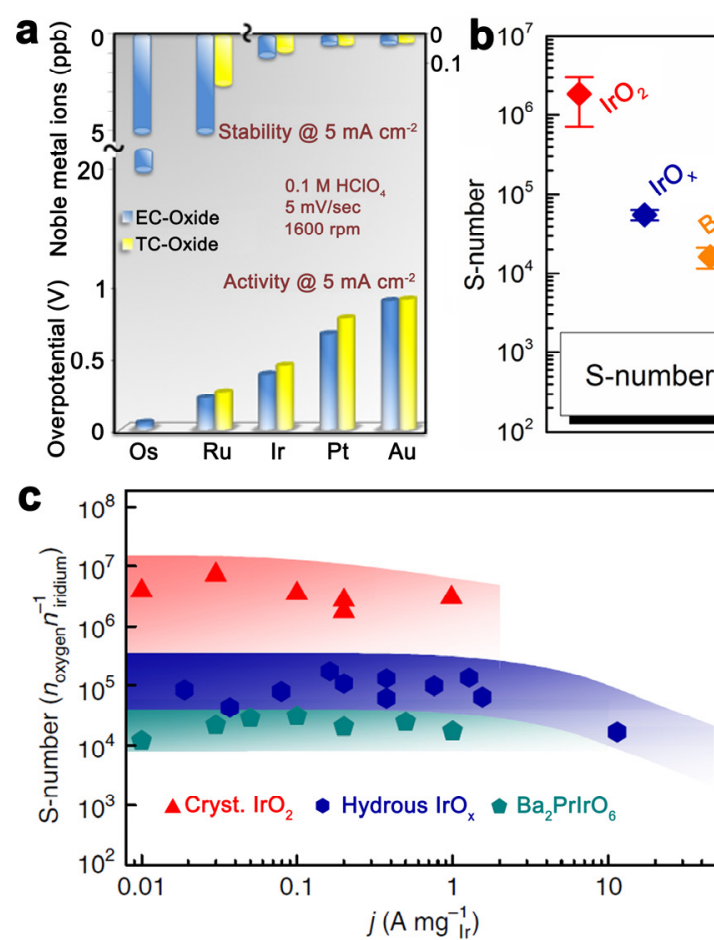
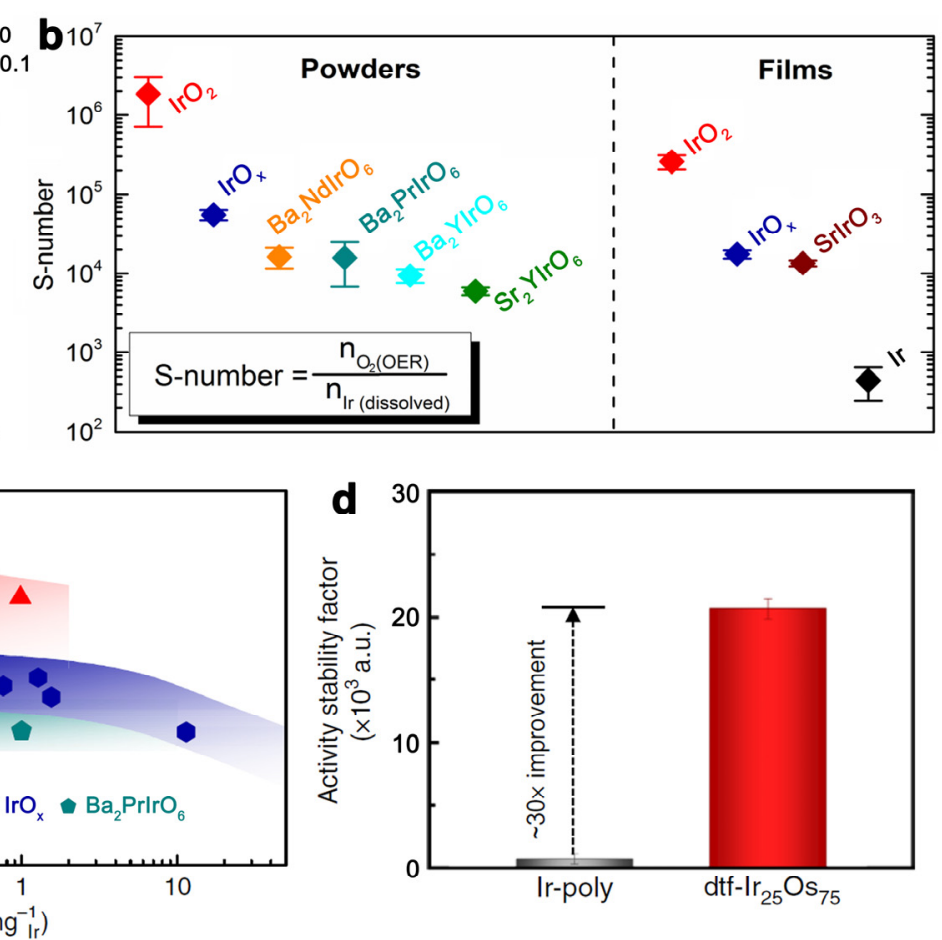

Fig. 5. (a) The inverse relationship between the stabilities of monometallic oxides and their reactivities for OER. Reproduced with permission [56]. Copyright 2014, American Chemical Society. (b) Stability number presented for iridium containing catalysts in thin film or powder form. (c) Stability number plotted versus mass specific current density for some iridium containing powder catalysts. (b,c) Reproduced with permission [60]. Copyright 2018, Nature Publishing Group. (d) The activity stability factor (ASF) for Ir-poly and dft-Ir ${ }_{25}$ Os75. Reproduced under the terms of the Creative Commons Attribution License. 

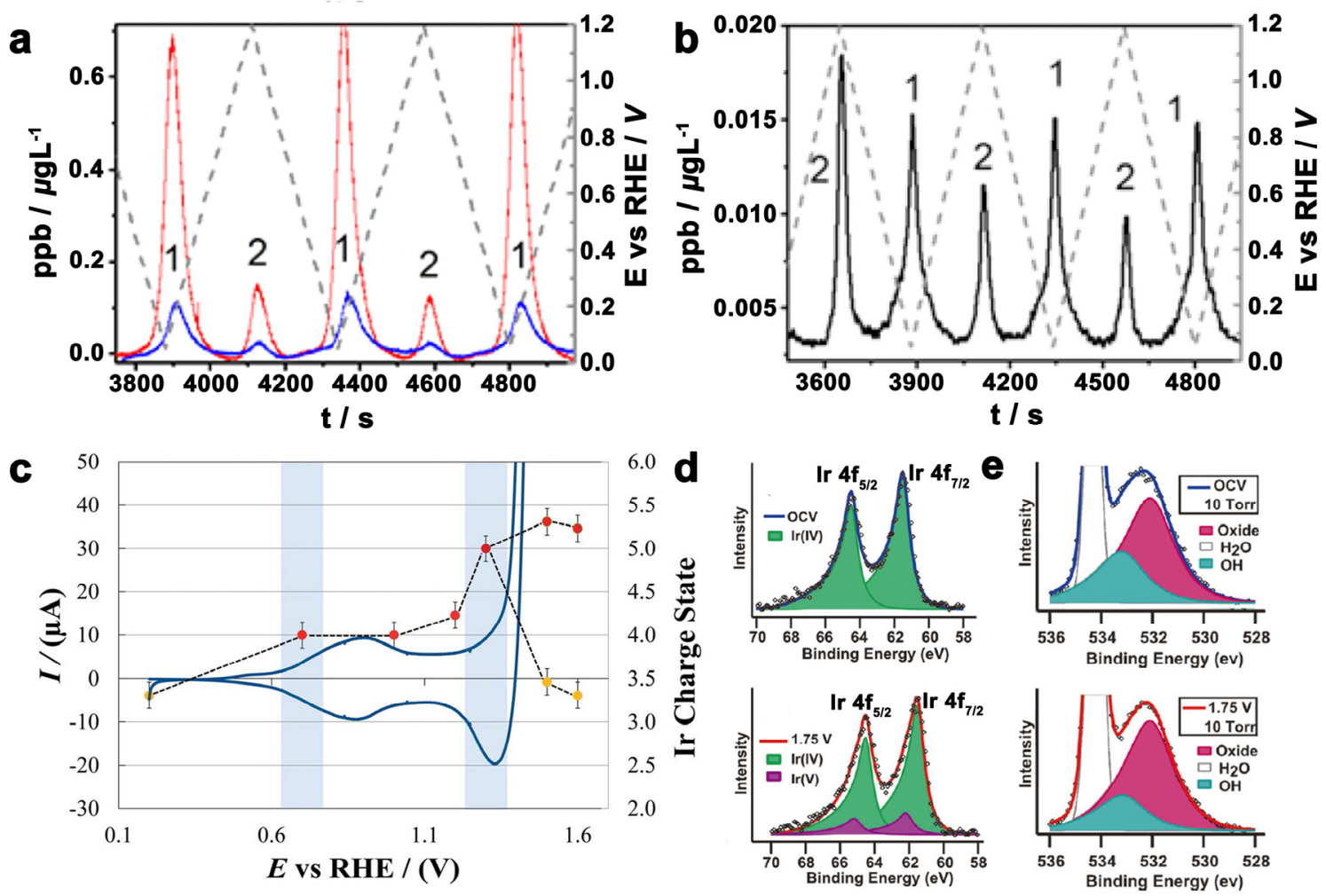

Fig. 6. Iridium dissolution profiles for (a) Ir black (red), electrochemically oxidized iridium (blue) and (b) thermally prepared $\mathrm{IrO}_{2}$ when cycling the catalysts from 0.05 to $1.2 \mathrm{~V}$. (a,b) Reproduced with permission [62]. Copyright 2017, American Chemical Society. (c) CV curves (left axis) and Ir oxidation state value at applied potentials (right axis) of EIROF. Reproduced with permission [65]. Copyright 2014, Royal Society of Chemistry. Ir $4 f$ (d) and $01 s$ (e) XPS spectrum under open circuit and oxygen evolution conditions. (d,e) Reproduced with permission [66]. Copyright 2014, Wiley-VCH.

calculated by Eq. (26).

$$
\mathrm{ASF}=\left.\frac{J-S}{S}\right|_{\eta}
$$

where $J$ is the catalytic current density, which is employed to represent the $\mathrm{O}_{2}$ production rate, $S$ is the dissolution current density, which is equivalent to the metal dissolution rate during OER, and $\eta$ stands for a constant overpotential [61]. A material with a higher ASF value tends to possess both superior activity and stability, suggesting that its balance of activity and stability may be closer to ideal. In their work, they used dealloyed $\mathrm{Ir}_{25} \mathrm{Os}_{75}$ thin films (dtf-Ir25Os75) as an example (Fig. 5(d)), which exhibited a factor of $~ 30$ improvement for ASF compared with Ir-based oxide materials ( $\left.\operatorname{Ir}_{\text {poly }}\right)$. However, it should be noted that the determination of $J$ and $S$ from experimentally measured faradaic currents is conducted using an in situ stationary probe rotating-disk electrode (SPRDE) coupled to an inductively coupled plasma-mass spectrometer (ICP-MS). This obvious equipment limitation may substantially impede the promotion of such parameters.

\section{Recent insights in structural evolution of Ir oxides under OER electrocatalysis}

Nanosized $\mathrm{IrO}_{2}$ is an OER electrocatalyst that is currently employed for commercial PEM water electrolyzers. With the substantial development of in situ characterization techniques, some new insights into the structural evolution of Ir oxides, including $\mathrm{IrO}_{2}$ and its relative $\mathrm{IrO}_{x}$, under OER electrocatalysis have been achieved recently.

The dissolution behavior of various Ir oxides under OER conditions is rather complicated. The influence factors include not only the nature of OER catalysts, such as crystallinity and composition, but also the external working environment (e.g., electrolyte and applied potential). Jovanovič et al. [62] systematically investigated the electrochemical dissolution of (1) pure metallic iridium (A-Ir), (2) electrochemically oxidized iridium (E-Ir), and (3) thermally prepared $\mathrm{IrO}_{2}\left(\mathrm{~T}-\mathrm{IrO}_{2}\right)$ under a high-sensitivity electrochemical flow cell (EFC) [62]. The results demonstrated that the corrosion stability increased in the order of A-Ir $<$ E-Ir $<\mathrm{T}$ - $\mathrm{IrO}_{2}$. Metallic iridium particles exhibited the most unstable nature, and the dissolution concentration of $\mathrm{T}$-IrO $\mathrm{I}_{2}$ was two orders of magnitude lower than those of $\mathrm{A}$-Ir and E-Ir. The authors further pointed out that both cathodic and anodic dissolutions were detected for Ir-based materials (Figs. 6(a,b)). Three possible dissolution pathways were proposed, including reduction dissolution (Eq. (27)), direct dissolution (Eq. (28)), and oxidation dissolution (Eq. (29)).

$$
\begin{aligned}
\mathrm{IrO}_{x}+2 x \mathrm{H}^{+}+2 \mathrm{xe}^{-} \rightarrow \mathrm{Ir}^{y+}+x \mathrm{H}_{2} \mathrm{O} \\
\mathrm{Ir} \rightarrow \mathrm{Ir}^{3+}+3 \mathrm{e}^{-} \\
\mathrm{Ir}_{2} \mathrm{O}_{3}+5 \mathrm{H}_{2} \mathrm{O} \rightarrow 2 \mathrm{IrO}^{-}-4+10 \mathrm{H}^{+}+6 \mathrm{e}^{-}
\end{aligned}
$$

Both A-Ir and $\mathrm{T}-\mathrm{IrO}_{2}$ were inferred to dissolve predominantly through the generation of unstable Ir species with a 
valence state $>+4$. The dissolution mechanism of E-Ir exhibited a different pathway, which mainly proceeded via the transient formation of Ir(IV) to Ir (III). In another work, Kasian et al. [63] monitored the degradation products of Ir and Ir oxides using a scanning flow cell coupled with online electrochemical mass spectrometry (OLEMS). The formation of $\mathrm{IrO}_{3}$ was observed for all the studied anodes, and $\mathrm{IrO}_{3}$ was considered to be one of the active phases for Ir-based materials. $\mathrm{IrO}_{3}$ either decomposes into $\mathrm{IrO}_{2}$ and $\mathrm{O}_{2}$ to generate an $\mathrm{O}_{2}$ product or interact with water to form soluble IrO2-4, leading to one of the major dissolution pathways for Ir oxides.

The valence state variations of Ir and 0 species in Ir oxides during catalytic reactions need to be carefully considered, and the actual existential forms of both Ir and 0 species are highly correlated to the corresponding mechanism for OER [64-70]. In order to identify the valence state of the Ir species, Minguzzi et al. [64] applied in situ X-ray absorption spectroscopy (XAS) to monitor the signal change and position shift at the Ir-LiII edge under oxygen evolution conditions. Electrodeposited iridium oxide film (EIROF) was chosen as the study object, and its highly hydrated property ensured that a considerable part of EIROF participated in the catalytic reaction. Using the spectra of powdered $\mathrm{IrCl}_{3}$ and $\mathrm{IrO}_{2}$ as a reference, the authors pointed out that Ir species in EIROF were present in both the Ir(III) and $\operatorname{Ir}(\mathrm{V})$ oxidation states during the OER (Fig. 6(c)), while there was no direct evidence to support the presence of Ir(IV) under water oxidation conditions. The same group further investigated three Ir oxides with different hydration degrees for the OER [65]. The coexistence of $\operatorname{Ir}(\mathrm{III})$ and $\operatorname{Ir}(\mathrm{V})$ was observed under $E \geq 1.3 \mathrm{~V}$ for various Ir oxides. The hydrated nanoparticles exhibited higher intrinsic activity and might possess an enhanced ability to generate $\operatorname{Ir}(\mathrm{V})$ sites and/or enhance proton mobility. In another study, Casalongue et al. [66] used ambient-pressure X-ray photoelectron spectroscopy to probe the change of Ir oxidation state for $\mathrm{IrO}_{2}$ nanoparticles. The Ir $4 f \mathrm{XPS}$ spectra showed that a fraction of the surface Ir(IV) sites transformed into $\operatorname{Ir}(\mathrm{V})$ species during the OER (Fig. 6(d)). Their results also demonstrated that the valence state variation was confined to the catalyst surface, and both $\operatorname{Ir}(\mathrm{IV})$ and $\operatorname{Ir}(\mathrm{V})$ oxidation states were present for $\mathrm{IrO}_{2}$ nanoparticles. In addition, the change in the Ir $4 f$ spectra was only detected under oxygen-evolving conditions, demonstrating the electrochemical reversibility of the Ir species. Moreover, by examining the $01 \mathrm{~s}$ spectra during OER (Fig. 6(e)), the authors monitored the reduction of adsorbed hydroxide on the catalyst surface. This result indicated that $\mathrm{IrO}_{2}$ nanoparticles favored a deprotonation pathway and went through the conversion from hydroxide to oxide.

The presence of a mixed-valence state of oxygen species in Ir oxides was first reported by Pfeifer et al. [67]. In contrast to rutile $\mathrm{IrO}_{2}$, a distinct resonance was identified for amorphous $\mathrm{IrO}_{x}$ at $529 \mathrm{eV}$ of 0 K-edge spectra using near-edge X-ray absorption fine structure (NEXAFS) measurements (Fig. 7(a)), and this resonance was associated with $\mathrm{O}^{\mathrm{I}}$. Based on this finding, the authors claimed that electrophilic $\mathrm{O}^{\mathrm{I}-}$ might play a key role in OER catalysis for amorphous $\mathrm{IrO}_{x}$. $\mathrm{O}^{\mathrm{I}}$ could be susceptible to the nucleophilic attack of water during OER, further leading to the enhancement of catalytic kinetics compared with rutile $\mathrm{IrO}_{2}$. The authors further confirmed the electrophilic nature of $\mathrm{O}^{\mathrm{I}-}$ species by introducing $\mathrm{CO}(\mathrm{g})$ to interact with rutile $\mathrm{IrO}_{2}$ and amorphous $\mathrm{IrO}_{x}$ in an $\mathrm{O}_{2}$-free reactor [68]. The results demonstrated that $\mathrm{CO}$ reacted with amorphous $\mathrm{IrO}_{x}$ through stoichiometric oxidation to generate $\mathrm{CO}_{2}$, but it did not react with rutile $\mathrm{IrO}_{2}$. Moreover, by using a PEM-based in situ technique combined with X-ray photoemission and absorption spectroscopy to investigate an initially metallic iridium model electrode [69], the authors found that $\mathrm{O}^{\mathrm{I}}$ species were generated reversibly when an anodic bias was imposed (Fig. 7(b)), and the concentration of $\mathrm{O}^{\mathrm{I}-}$ increased with the magnitude of the OER reactivity (Fig. 7(c)). A detailed mechanism was proposed by the authors, as shown in Eq. (30). This mechanism further emphasizes the crucial role of $\mathrm{O}^{\mathrm{I}-}$ sites of amorphous $\mathrm{IrO}_{x}$ in the OER catalytic cycle.

$\mathrm{IrO}_{x} \mathrm{O}^{\mathrm{I}-}+\mathrm{H}_{2} \mathrm{O} \rightarrow \mathrm{IrO}_{x} \mathrm{O}^{\mathrm{I}-}-\mathrm{O}^{\mathrm{I}-}-\mathrm{H}+\mathrm{H}^{+}+\mathrm{e}^{-} \rightarrow \mathrm{IrO}_{x}+\mathrm{O}_{2}+2 \mathrm{H}^{+}+3 \mathrm{e}^{-}$

In another interesting work, Li et al. [44] investigated the first few atomic layers of electrochemically grown iridium oxide using atom probe tomography, and found that the as-formed amorphous Ir oxides gradually transformed into crystalline $\mathrm{IrO}_{2}$ by prolonging the anodic polarization, together with a loss of catalytic activity and stability enhancement. By combining with the isotope-labeled electrolyte, the authors further observed different interaction behaviors of hydroxy groups for amorphous Ir oxides and crystalline $\mathrm{IrO}_{2}$ islands. Hydroxy groups permeated into the electrochemical oxide particles after anodic oxidation for $4 \mathrm{~h}$, while water and hydroxyl groups only covered the surface of the electrochemical oxide after anodic polarization for $120 \mathrm{~h}$. An activity increase during the first $4 \mathrm{~h}$ was also captured by the authors, who pointed out that the as-identified non-stoichiometric $\mathrm{IrO}_{x}$ species would make the adsorption of oxygen-containing radicals more energetically favored, further resulting in higher OER electrocatalytic activity.

The determination of the structural evolution of $\operatorname{IrO}_{2}\left(\mathrm{IrO}_{x}\right)$ during OER is a prerequisite for the identification of the catalytic mechanism involved in the OER. However, it is quite difficult to obtain comprehensive information about the structural evolution of $\mathrm{IrO}_{2}\left(\mathrm{IrO}_{x}\right)$ during the OER because of the complexity of solid-liquid interfacial electrocatalysis, the mutability of material microstructures, and the lack of high sensitivity for operando characterization technologies. Therefore, a commonly accepted understanding of both the structural evolution and catalytic mechanism for $\mathrm{IrO}_{2}\left(\mathrm{IrO}_{x}\right)$ is still not available, and a more advanced characterization combination is needed to solve this crucial issue.

\section{Low-iridium oxygen evolution electrocatalysts}

For the development of acidic OER catalysis, several effective strategies have been reported to enhance the catalytic performance of Ir-based catalysts, including (1) investigating the morphology effect to enlarge the surface-active sites, (2) introducing heteroatoms into pure iridium oxides, and (3) combining with support materials to build catalyst/support 



Fig. 7. (a) O K-edge spectra of $\mathrm{IrO}_{2}$ and amorphous $\mathrm{IrO}_{x}$. Reproduced with permission [67]. Copyright 2016, Royal Society of Chemistry. (b) 0 K-edge spectra of Ir-coated PEM during and after OER. (c) 0 K-edge spectra of Ir-coated PEM at successively applied potentials. (b,c) Reproduced with permission [69]. Copyright 2017, Royal Society of Chemistry.

systems, and (4) constructing iridates with complex crystal structures to design low-iridium catalysts. The as-designed low-iridium catalysts generally exhibit high iridium utilization efficiency, adjustable electronic structure, and enriched connection pattern of $\mathrm{IrO}_{6}$ subunits. In this section, representative examples are presented to demonstrate the structure-activity relationship of low-iridium catalysts.

\subsection{Heteroatoms-containing $\operatorname{IrO}_{2}\left(\operatorname{IrO}_{x}\right)$-based catalysts}

Introducing Ru species into pure iridium oxides is the most common strategy to enhance the catalytic activity of Ir-based catalysts. $\mathrm{Ru}$ oxides have a superior OER intrinsic activity compared to Ir oxides, but they suffer from poor stability due to the generation of soluble species with a high oxidation state (e.g., $\mathrm{RuO}_{4}{ }^{2-}$ ) under acidic OER conditions [71]. In order to combine the advantages of Ir and Ru oxides, Ir-Ru bimetallic oxides have been continually investigated since the early the 1990s [23]. The reported Ir-Ru bimetallic catalysts always exhibit better catalytic activity than pure iridium oxides. However, the investigation of the dissolution behavior during the catalytic reaction is insufficient, and the possible stabilizing effect of Ir species for specified materials is also ambiguous.

Kötz et al. [72] observed that even a small amount of $\mathrm{IrO}_{2}$ $(\sim 20 \mathrm{wt} \%)$ could significantly enhance the corrosion stability of bimetallic Ir-Ru oxides, and they claimed that the stability enhancement originated from the electronic effect. The authors thought that the $\mathrm{IrO}_{2}$ domains in the material shared electrons with the constituent $\mathrm{RuO}_{2}$, and thereby inhibited the formation of soluble $\mathrm{RuO}_{4}^{2-}$ under electrocatalysis conditions. This viewpoint is a general explanation to rationalize this stabilizing effect, but it is not the only one. By using a surface segregation strategy to design stable Ru-Ir oxides, the Markovic group pointed out that the stabilization of Ru by Ir was probably governed by in situ formed $\mathrm{IrO}_{x}$ protective skins [73]. In another example, the Qiao group designed a core-shell $\mathrm{Ru} @ \mathrm{IrO}_{x}$ heterostructured nanomaterial for acidic OER [71]. For comparison, the authors synthesized a Ru-Ir oxide alloy $\left(\mathrm{RuIrO}_{x}\right)$. The trend in OER specific activity was found to be $\mathrm{Ru} @ \mathrm{IrO}_{x}>\mathrm{RuO}_{2}>$ $\mathrm{RuIrO}_{x}>\mathrm{IrO}_{2}$. The remarkable activity of Ru@IrO ${ }_{x}$ was ascribed to a strong charge redistribution between $\mathrm{Ru}$ and $\mathrm{IrO}_{x}$, generating an electron-deficient $\mathrm{IrO}_{x}$ shell. In addition to its high catalytic activity, Ru@IrO ${ }_{x}$ exhibited good catalytic and structural stability. The concentration of Ru species in the electrolyte for the Ru@IrO ${ }_{x}$-catalyzed OER was found to be 30 -fold lower than that for the $\mathrm{RuIrO}_{x}$-catalyzed OER (Figs. 8(a,b)). The good structural stability of Ru@ $\mathrm{IrO}_{x}$ was mainly due to the protective function of the $\mathrm{IrO}_{x}$ shell. In addition, Wang et al. [74] synthesized low-crystalline $\mathrm{Ir}_{0.7} \mathrm{Ru}_{0.3} \mathrm{O}_{x}$ (EC) from metallic $\mathrm{Ir}_{0.7} \mathrm{Ru} 0.3$ using electrochemical oxidation and high-crystalline $\mathrm{Ir}_{0.7} \mathrm{Ru}_{0.3} \mathrm{O}_{2}$ (TT) through thermal oxidation. Their catalytic results demonstrated that $\operatorname{Ir}_{0.7} \mathrm{Ru}_{0.3} \mathrm{O}_{x}$ (EC) exhibited approximately 13 times higher activity than $\mathrm{Ir}_{0.7} \mathrm{Ru}_{0.3} \mathrm{O}_{2}$ (TT) (Fig. 8(c)), but the former gave much worse corrosion stability than the 

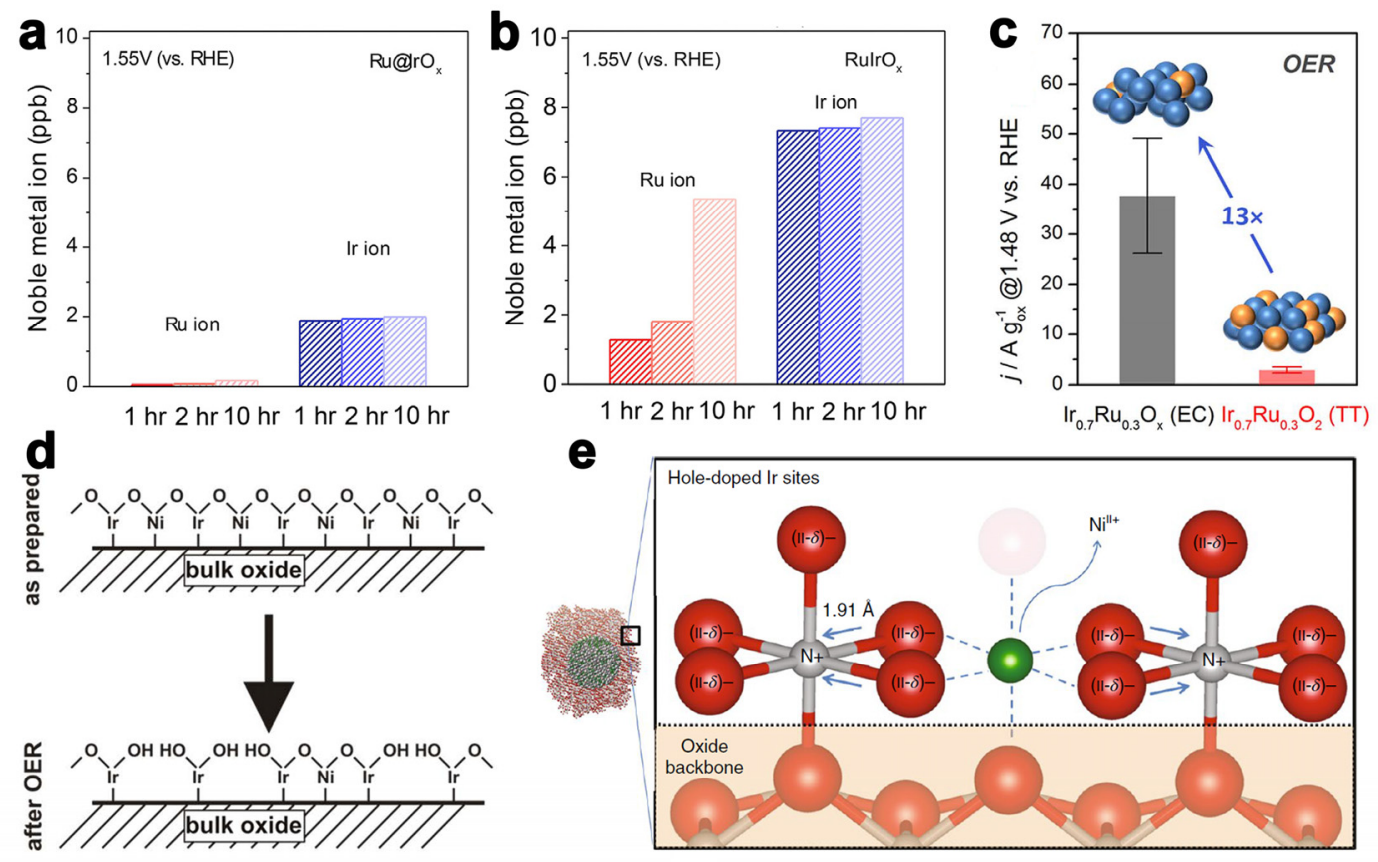

Fig. 8. Dissolved Ru and Ir for (a) Ru@ $\mathrm{IrO}_{x}$ and (b) $\mathrm{RuIrO}_{x}$ at different times. Reproduced with permission [71]. Copyright 2019, Elsevier. (c) Mass activity comparison between $\mathrm{Ir}_{0.7} \mathrm{Ru}_{0.3} \mathrm{O}_{x}$ (EC) and $\mathrm{Ir}_{0.7} \mathrm{Ru}_{0.3} \mathrm{O}_{2}$ (TT). Reproduced with permission [74]. Copyright 2017, Elsevier. (d) Schematic illustration of the Ni leaching from the surface of Ir-Ni mixed oxides. Reproduced with permission [75]. Copyright 2015, American Chemical Society. (e) Schematic illustration of catalytic sites in $\mathrm{IrNiO}_{x}$ nanoparticles. Reproduced with permission [76]. Copyright 2018, Nature Publishing Group.

latter, revealing the importance of the high degree of crystallinity in $\mathrm{Ru}(\mathrm{Ir}) \mathrm{O}_{2}$ to achieve high structural stability.

In addition to $\mathrm{Ru}$, several nonprecious metals have also been introduced in $\mathrm{IrO}_{2}\left(\mathrm{IrO}_{x}\right)$-based oxides to enhance catalytic activity and/or stability. Transition metals, especially $\mathrm{Ni}$ and Co, are the most prominent ones to be investigated [50], but these transition metals cannot remain stable during acidic OER, and surface self-reconstruction always occurs during the OER. For instance, Reier et al. [75] presented a class of Ir-Ni oxide thin films with tunable compositions as model catalysts for acidic OER. The Ir-Ni mixed oxides were shown to offer a 20 -fold improvement in the Ir mass-based OER activity over pure $\mathrm{IrO}_{x}$. The effect of $\mathrm{Ni}$ on the activity enhancement was explained by a rational speculation that the unstable $\mathrm{Ni}$ dissolution for Ir-Ni mixed oxides during OER facilitated the formation of $\mathrm{OH}$ groups on the surface structure, which served as reactive surface intermediates for promoting OER (Fig. 8(d)). To understand the effect of nickel at the atomic level, Nong et al. [76] systematically compared the local geometric ligand environment and electronic states of oxygen-coordinated iridium centers in Ir@IrO $x$ and IrNi@IrO $x$ using operando techniques under OER conditions. The operando measurement results revealed that compared with $\mathrm{IrO}_{x}$ and rutile-type $\mathrm{IrO}_{2}, \mathrm{IrNiO}_{x}$ exhibited more $d$-band holes and uniquely shortened Ir-O bond lengths after $\mathrm{Ni}$ dissolution, and the covalency trend of the Ir-O bond increased in the order of rutile-type $\mathrm{IrO}_{2}<\mathrm{IrO}_{x}<\mathrm{IrNiO}_{x}$. These results were further strengthened by DFT calculations, which revealed that introducing metal defects into theoretical models would increase the formal number of iridium d-band holes $(\Delta d)$ to- gether with decreasing the average Ir-O bond length. The DFT results also showed that an increase in the iridium vacancy density could lead to an increase in unoccupied oxygen $2 p$ states, resulting in the formation of $\mathrm{O}^{\mathrm{I}-}$ or $\mathrm{O}^{(\mathrm{II}-\delta)-}$ species. The presence of electrophilic $\mathrm{O}^{\mathrm{I}-}$ or $\mathrm{O}(\mathrm{II}-\delta)-$ species was believed to endow a faster OER process through the nucleophilic acid-base 0-0 formation process, as illustrated in Fig. 8(e).

In another example, the Liu group reported a simple lithium incorporation method that broke long-range order of [ $\mathrm{IrO}_{6}$ ] octahedrons in iridium oxide to form highly efficient amorphous $\mathrm{Li}^{-} \mathrm{IrO}_{x}$ [77]. The overpotential at $10 \mathrm{~mA} / \mathrm{cm}^{2}$ geo for amorphous $\mathrm{Li}^{-\mathrm{IrO}_{x}}$ is $290 \mathrm{mV}$, which is much lower than that (435 mV) for $\mathrm{IrO}_{2}$. High-angle annular dark-field scanning transmission electron microscopy (HAADF-STEM) images and EXAFS results confirmed that similar [ $\left.\mathrm{IrO}_{6}\right]$ octahedral units resided in both $\mathrm{Li}^{-\mathrm{IrO}_{x}}$ and $\mathrm{IrO}_{2}$, while the [ $\mathrm{IrO}_{6}$ ] octahedron connection modes of the two samples were quite different. More specifically, the $\left[\mathrm{IrO}_{6}\right]$ octahedrons in rutile $\mathrm{IrO}_{2}$ were supposed to interconnect periodically with each other in a corner-/edge-sharing form, while in the case of $\mathrm{Li}^{-} \mathrm{IrO}_{x},\left[\mathrm{IrO}_{6}\right]$ octahedrons are interconnected randomly, and lithium ions reside inside the structure. In addition, an increase in the iridium oxidation state for $\mathrm{Li}^{-} \mathrm{IrO}_{x}$ and shrinkage of the Ir-O bond distance were observed during OER, owing to the flexible structure of $\mathrm{Li}^{-} \mathrm{IrO}_{x}$. In contrast, no difference was observed in rutile $\mathrm{IrO}_{2}$ under the same conditions, suggesting that the redox behavior of Ir was largely limited by the rigid structure. Based on the above results, the authors believed that the higher oxidation state of iridium species and short Ir-O distance made the 
iridium species more electrophilic and benefited the oxidation of hydroxyls and the formation of $\mathrm{O}-\mathrm{O}$ bonds.

\subsection{Perovskite-type iridium-based catalysts}

Designing and synthesizing complex iridium-based oxides is another effective strategy for enlarging the atom utilization of iridium in iridium-based materials. The exploration of appropriate Ir-based crystal structures for OER can be traced back to 1995 [78]. This field did not attract enough attention until Seitz's report about $\mathrm{SrIrO}_{3}$ in 2016 [79]. After this work, a number of Ir-based perovskites with various distinct structures have been studied for acidic OER (see Table 1). Through this strategy, alkaline-earth metals and/or rare-earth metals are introduced in various crystal structures, and the content of iridium can be largely diluted. Moreover, the intrinsic activity of the iridium active site could be further improved by rational electronic modulation.

Orthorhombic $\mathrm{SrIrO}_{3}$ with a pseudo-cubic structure is a type of typical perovskite [80]. This phase of $\mathrm{SrIrO}_{3}$ is actually metastable in nature, and a high-pressure, high-temperature condition is usually needed to achieve this unique structure [81]. As mentioned before, Seitz et al. [79] synthesized epitaxial $\mathrm{SrIrO}_{3}$ films deposited on $\mathrm{SrTiO}_{3}$ substrates using pulsed laser deposition. During electrochemical measurements, they found that the OER activity of $\mathrm{SrIrO}_{3}$ needed approximately two hours to reach the optimum, and outperformed the rutile $\mathrm{IrO}_{2}$ film by two orders of magnitude. By using combined characterizations, a leaching of $\mathrm{Sr}$ species was captured on the surface of $\mathrm{SrIrO}_{3}$, and the Sr content decreased to about $20 \%$ of its original value after $24 \mathrm{~h}$ of testing, with the content of Ir remaining constant. The results demonstrated that the in situ-formed $\mathrm{IrO}_{x} / \mathrm{SrIrO}_{3}$ was the real active phase for the OER. Their systematic DFT calculations showed that the formation of a surface phase with a structure similar to that of anatase $\mathrm{IrO}_{2}$ or $\mathrm{IrO}_{3}$ was responsible for the experimentally excellent activity [79].

The additional introduction of nonprecious metals into pseudo-cubic $\mathrm{SrIrO}_{3}$ to form double perovskites, denoted as $\left(\mathrm{AA}^{\prime}\right) \mathrm{B}_{2} \mathrm{O}_{6}$ or $\mathrm{A}_{2}\left(\mathrm{BB}^{\prime}\right) \mathrm{O}_{6}$, could further enhance the catalytic performance and reduce the Ir content in the catalysts [40]. Through the adjustment of the A' or B' sites in double perovskites, an optimized orbital filling of the catalytic sites would be reached with appropriate charge distribution and firm crystal architecture [82-85]. For the B' site adjustment, Diaz-Morales et al. [82] reported a family of iridium double perovskites $\left(\mathrm{Ba}_{2} \mathrm{MIrO}_{6}\right.$, with $\mathrm{M}=\mathrm{Y}, \mathrm{La}, \mathrm{Ce}, \mathrm{Pr}, \mathrm{Nd}$, and $\mathrm{Tb}$ ) containing 32 wt $\%$ less iridium than $\mathrm{IrO}_{2}$ as acidic OER catalysts. All Ir-based double perovskites exhibited more than threefold higher OER catalytic performances compared with $\mathrm{IrO}_{2}$, in an activity order of $\mathrm{Ce} \approx \mathrm{Tb} \approx \mathrm{Y}<\mathrm{La} \approx \mathrm{Pr}<\mathrm{Nd}$. Surface enrichment in iridium was observed after testing, and the surface Ba content was reduced three- to fourfold in the pristine compound. The authors pointed out that a lattice strain caused by lanthanides or yttrium substitution at the B' site improved the OER activity of perovskites by weakening the oxygen adsorption energy. Their results also suggested that a 3D network of corner-shared octahedra in perovskites as prerequisites was necessary for en- hanced Ir intrinsic activity, and Ba leaching further led to exposure of these highly active iridium centers [82].

Despite their high activity, these double perovskites often undergo great dissolution of non-noble elements at the A and $B$ sites during the OER in acid, leading to unsatisfactory structural stability. Therefore, more stable species such as $\mathrm{Ti}$ or $\mathrm{Zr}$ are intended to alloy into $\mathrm{SrIrO}_{3}$. Based on this consideration, our group synthesized porous $\mathrm{SrTiO}_{3}-\mathrm{SrIrO}_{3}$ solid solution nanotubes through an electrospinning method. The $\mathrm{SrTiO}_{3}-\mathrm{SrIrO}_{3}$ catalysts with 56 wt $\%$ less Ir than $\mathrm{IrO}_{2}$ exhibited more than 10 times higher OER catalytic activity, and could retain the original perovskite structure during testing. We found that the catalysts generated Sr-deficient surfaces on $\mathrm{SrTiO}_{3}-\mathrm{SrIrO}_{3}$ solid solutions under acidic electrocatalysis, and in situ formed $\mathrm{IrO}_{x}-\mathrm{TiO}_{x}$ solid solutions were the active species for the OER. To understand the origin of their high activities, we theoretically investigated the OER performances of rutile- and anatase-type $\mathrm{TiO}_{2}-\mathrm{IrO}_{2}$ solid solutions [86]. DFT results revealed that anatase-type $\mathrm{TiO}_{2}-\mathrm{IrO}_{2}$ solid solutions had more active Ir catalytic sites (around the top of the OER volcano plot) than the benchmark $\mathrm{IrO}_{2}$ catalysts, while rutile-type $\mathrm{TiO}_{2}-\mathrm{IrO}_{2}$ solid solutions do not possess. These results suggest that Sr-etching-induced anatase-type $\mathrm{TiO}_{2}-\mathrm{IrO}_{2}$ on the perovskite surface was the activity origin of $\mathrm{SrIrO}_{3}-\mathrm{SrTiO}_{3}$ solid solutions. This work also inspired us to alloy catalytically inert $\mathrm{SrZrO}_{3}$ in $\mathrm{SrIrO}_{3}$ to form a perovskite-type solid solution electrocatalyst for OER [53]. Similarly, the $\mathrm{SrZrO}_{3}-\mathrm{SrIrO}_{3}$ electrocatalyst was considered to generate an anatase-type $\mathrm{ZrO}_{2}$ - $\mathrm{IrO}_{2}$ solid solution on the surface as the active phase. The catalyst was among the most active Ir-based OER electrocatalysts in acid. Furthermore, elemental analysis during electrochemical testing confirmed that the alloying effects of the oxide solid solutions resulted in an improved structural stability relative to $\mathrm{Zr}$-free catalysts.

$6 \mathrm{H}-\mathrm{SrIrO}_{3}$ with a monoclinic structure is another promising Ir-based perovskite for acidic OER, which exhibits distortion of the hexagonal $\mathrm{BaTiO}_{3}$ structure $[81,87,88]$, and can be classified into the class of hexagonal perovskites [89]. As shown in the structural representation (Fig. 9(a)), alternated face-sharing $\mathrm{IrO}_{6}$ octahedral dimers and corner-sharing $\mathrm{IrO}_{6}$ octahedra along the $\mathrm{c}$ axis constitute the B-O framework of $6 \mathrm{H}_{-} \mathrm{SrIrO}_{3}$ [87]. Moreover, the Ir-O bond distances in the face-shared octahedral dimers are much larger than those in isolated $\mathrm{IrO}_{6}$ octahedra or in $\mathrm{IrO}_{2}$ (2.005-2.885 $\AA$ vs. 1.978-1.982 ̊), demonstrating a weaker bond energy, which may exhibit unique catalytic features for O-relevant adsorbates. Our group first identified the superior OER performance of $6 \mathrm{H}_{-} \mathrm{SrIrO}_{3}$, which could achieve $10 \mathrm{~mA} / \mathrm{cm}^{2}$ geo at a small overpotential of $\sim 248 \mathrm{mV}$. The geometric area-normalized catalytic activity of $6 \mathrm{H}-\mathrm{SrIrO}_{3}$ is about four times higher than that of $\mathrm{IrO}_{2}$ at $1.525 \mathrm{~V}$, and the corresponding mass activity is approximately seven times higher than that of $\mathrm{IrO}_{2}$. We further compared $6 \mathrm{H}-\mathrm{SrIrO}_{3}$ with pseudo-cubic $\mathrm{SrIrO}_{3}\left(3 \mathrm{C}\right.$-SrIrO $\left.\mathrm{S}_{3}\right)$ under similar synthesis conditions, and the results showed that $6 \mathrm{H}_{-} \mathrm{SrIrO}_{3}$ had a higher catalytic activity and structural stability than 3C-SrIrO ${ }_{3}$. Similar to the observations of Seitz et al. [79], $\sim 24 \%$ of the $\mathrm{Sr}$ content was deviated from the material with surface amorphorization formed in the case of $3 \mathrm{C}$-SrIrO $\mathrm{S}_{3}$ during 

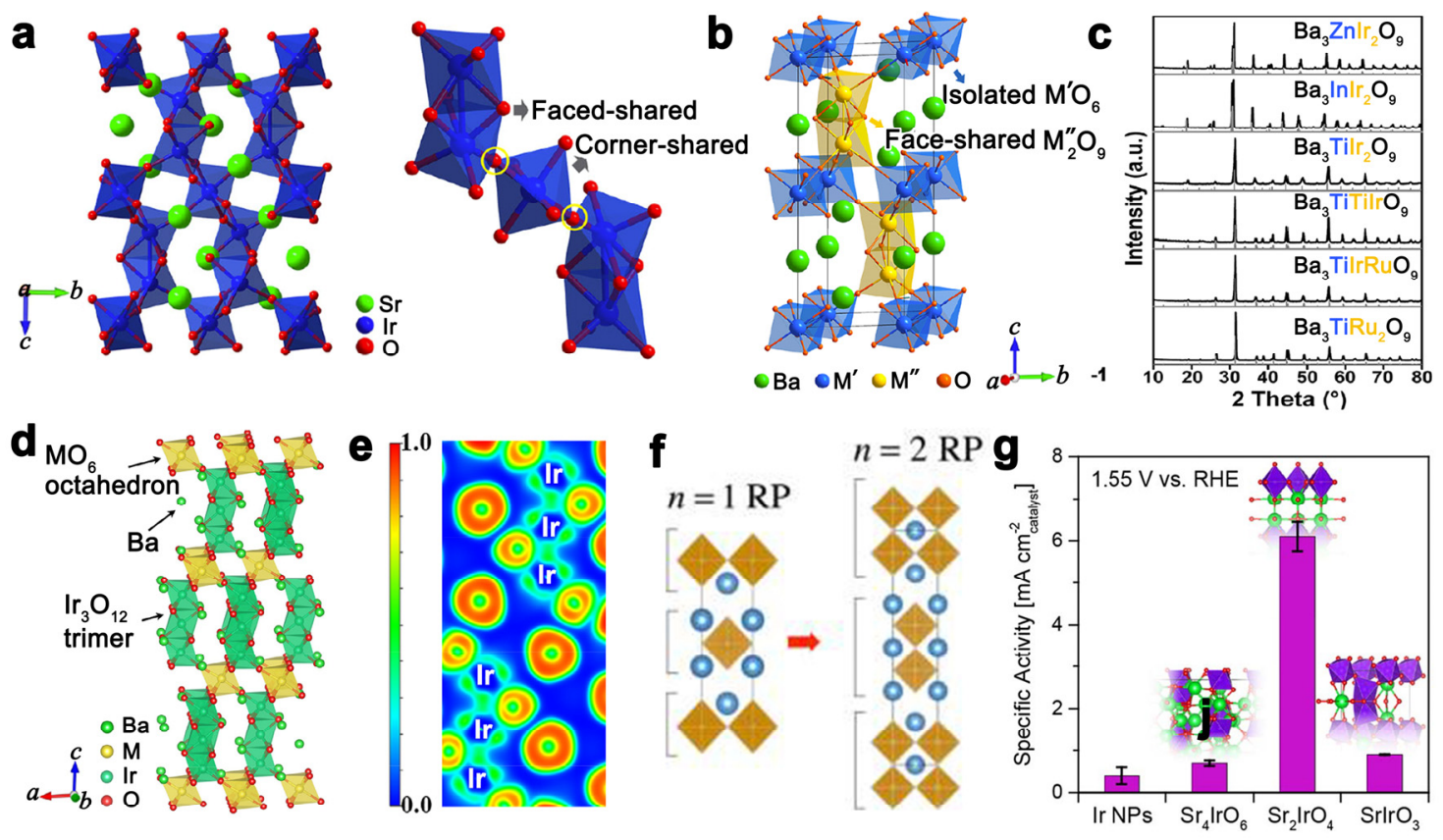

Fig. 9. (a) Crystal structure of $6 \mathrm{H}_{-} \mathrm{SrIrO}_{3}$. Reproduced with permission [87]. Copyright 2018, Nature Publishing Group. (b) Crystal structure of $\mathrm{Ba}_{3} \mathrm{M}^{\prime} \mathrm{M}_{2}{ }_{2} \mathrm{O}_{9}$ triple perovskites. (c) XRD patterns of $\mathrm{Ba}_{3} \mathrm{M}^{\prime} \mathrm{Ir}_{2} \mathrm{O}_{9}$. (b,c) Reproduced with permission [91]. Copyright 2020, American Chemical Society. (d The crystal structure and (e) electron location function (ELF) of 12L-perovskites (Ba4 $\mathrm{MIr}_{3} \mathrm{O}_{12}$ ). (d,e) Reproduced with permission [90]. Copyright 2020, Elsevier. (f) The structure of Ruddlesden-Popper (RP) phases with $\left(\mathrm{ABO}_{3}\right)_{n=1} /(\mathrm{AO})$ formula. Reproduced with permission [93]. Copyright 2014, American Chemical Society. (g) Specific OER activity of Sr iridates in 0.1 M HClO . Reproduced with permission [94]. Copyright 2017, American Chemical Society.

the OER, while only $\sim 1.3 \%$ of the total Sr content leached for $6 \mathrm{H}-\mathrm{SrIrO}_{3}$ with a well-preserved crystal structure. In combination with the DFT calculations, a smaller theoretical overpotential of the Ir site in face-shared octahedra suggested that such dimers made a main contribution to the catalytic performance of $6 \mathrm{H}_{-} \mathrm{SrIrO}_{3}$, and the weakened surface Ir-O binding facilitated the transition from $\mathrm{O}^{*}$ to $\mathrm{HOO}^{*}$ as the potential-determining step of $6 \mathrm{H}-\mathrm{SrIrO}_{3}$ [87].

Our group also performed some interesting works for searching more Ir-based perovskites comprising face-shared octahedral dimers [90-92]. To further identify the possible structure-activity relationship under the scale of subunit, we synthesized a family of $\mathrm{Ba}_{3} \mathrm{M}^{\prime} \mathrm{M}^{\prime \prime}{ }_{2} \mathrm{O}_{9}$ triple perovskites with different $\mathrm{B}$-site coordination environment (isolated $\mathrm{M}^{\prime} \mathrm{O}_{6}$ octahedra and face-shared $\mathrm{M}^{\prime \prime}{ }_{2} \mathrm{O}_{9}$ dimers) and tunable B-site elemental composition ( $\mathrm{M}^{\prime}=\mathrm{Ti}, \mathrm{In}, \mathrm{Zn} ; \mathrm{M}^{\prime \prime}{ }_{2}=$ IrIr, TiIr, IrRu, RuRu) (Figs. 9(b,c)) [91]. Electrocatalytic measurements together with theoretical results revealed that face-shared $\mathrm{M}_{2}{ }_{2} \mathrm{O}_{9}$ dimers governed the OER activity and stability for $\mathrm{Ba}_{3} \mathrm{M}^{\prime} \mathrm{M}^{\prime \prime}{ }_{2} \mathrm{O}_{9}$ under acidic conditions, and $\mathrm{M}^{\prime} \mathrm{O}_{6}$ octahedra as auxiliary subunit regulated the metal-oxygen covalency and oxygen p states in the structure. Among them, $\mathrm{Ba}_{3} \mathrm{TiIr}_{2} \mathrm{O}_{9}$ containing essential $\mathrm{Ir}_{2} \mathrm{O}_{9}$ subunits exhibited the best catalytic performance, which was 28 times higher iridium mass activity than that of $\mathrm{IrO}_{2}$. It should also be noted that a thin amorphous layer $(\sim 1 \mathrm{~nm})$ formed on the surface of $\mathrm{Ba}_{3} \mathrm{TiIr}_{2} \mathrm{O}_{9}$ during the OER, with about $2.1 \%$ and $1.6 \%$ of the total $\mathrm{Ba}$ and $\mathrm{Ti}$ contents leached into the electrolyte, while the bulk structure of the perovskite was well preserved [91]. Following this, we then examined a series of $\mathrm{Ba}_{3} \mathrm{LnIr}_{2} \mathrm{O}_{9}$ (Ln = lanthanides) using DFT calculations. Ir sites in the $\mathrm{Ir}_{2} \mathrm{O}_{9}$ dimer were found to be the active sites for OER, and their intrinsic activity could be regulated by the $\mathrm{LnO}_{6}$ octahedra [92].

In another work, we synthesized a class of iridium-based 12L-perovskites $\left(\mathrm{Ba}_{4} \mathrm{MIr}_{3} \mathrm{O}_{12}, \mathrm{M}=\mathrm{Pr}, \mathrm{Bi}, \mathrm{Nb}\right)$ with unique trinuclear $\mathrm{Ir}_{3} \mathrm{O}_{12}$ subunits [90]. The $\mathrm{Ir}_{3} \mathrm{O}_{12}$ trimers and $\mathrm{MO}_{6}$ octahedra are corn-shared connected along the $c$ axis in $\mathrm{Ba}_{4} \mathrm{MIr}_{3} \mathrm{O}_{12}$, forming a 12-layer structure (Figs. 9(d,e)). The acidic treatment result $\left(0.1 \mathrm{M} \mathrm{HClO}_{4}, 30 \mathrm{~d}\right)$ showed that this kind of perovskite retained its bulk structures under acidic conditions due to the firm $\mathrm{Ir}_{3} \mathrm{O}_{12}$ subunits in the structure. Further electrochemical measurements showed that the OER activity of this polymorphic structure followed a sequence of $\mathrm{Ba}_{4} \mathrm{PrIr}_{3} \mathrm{O}_{12}>\mathrm{Ba}_{4} \mathrm{BiIr}_{3} \mathrm{O}_{12}$ $>\mathrm{Ba}_{4} \mathrm{NbIr}_{3} \mathrm{O}_{12}$, and the mass activity of $\mathrm{Ba}_{4} \mathrm{PrIr}_{3} \mathrm{O}_{12}$ was 15.6 times higher than that of $\mathrm{IrO}_{2}$. As for the surface reconstruction, we found that the $7 \mathrm{~nm}$-depth surface region became amorphous during the OER in the case of $\mathrm{Ba}_{4} \mathrm{PrIr}_{3} \mathrm{O}_{12}$, and around $95 \%$ of $\mathrm{Ba}$ and $74 \% \mathrm{Pr}$ leached in the electrolyte. $\mathrm{MIrO}_{\mathrm{x}}(\mathrm{M}=\mathrm{Pr}$, $\mathrm{Bi}, \mathrm{Nb}$ ) covered the surface of $\mathrm{Ba}_{4} \mathrm{MIr}_{3} \mathrm{O}_{12}$ after the OER, and a large fraction of highly under-coordinated $\mathrm{Ir}^{5+}$ species generated during testing were supposed to contribute to the superior activity of $\mathrm{Ba}_{4} \operatorname{PrIr}_{3} \mathrm{O}_{12}$ [90].

In addition to the pseudo-cubic and monoclinic structures of Ir-based perovskites, some novel subunits and possible relationships between specific subunits and catalytic performance under the framework of perovskites have also been investigat- 
ed. Ruddlesden-Popper (RP) phases $\left(\left(\mathrm{ABO}_{3}\right)_{n=1} /(\mathrm{AO})\right)$ are a type of perovskite that consists of alternating layers of $\mathrm{AO}$ rock salt and $\mathrm{ABO}_{3}$ perovskite block, and exhibit a distinct layered two-dimensional topology (Fig. 9(f)) [93-95]. Strickler et al. [94] examined the acidic OER activity of $\mathrm{Sr}_{2} \mathrm{IrO}_{4}, \mathrm{Sr}_{4} \mathrm{IrO}_{6}$, and monoclinic $\mathrm{SrIrO}_{3}$ with similar micrometer-scale sizes. The results showed that specific catalyst activities normalized to the BET surface area increased in the order of commercial Ir/C $<\mathrm{Sr}_{4} \mathrm{IrO}_{6}<\mathrm{SrIrO}_{3}<\mathrm{Sr}_{2} \mathrm{IrO}_{4}$ (Fig. 9(g)), and $\mathrm{Sr}_{2} \mathrm{IrO}_{4}$ exhibited a 40 -fold increase in mass activity compared to $\mathrm{IrO}_{x}$. Moreover, all Sr iridates displayed higher activity than $\mathrm{IrO}_{x}$, although all of those suffered from both $\mathrm{Sr}$ and Ir dissolution, demonstrating the essential roles of the starting crystal structure and the initial presence of $\mathrm{Sr}$ for OER activity. By investigating the structure transition during OER, the authors also found that the higher initial Sr content the starting crystal structure possess, the higher amounts of $\mathrm{Sr}$ and Ir dissolution the corresponding surface underwent. The reason behind this phenomenon was that the phase with higher initial Sr content was more vulnerable to $\mathrm{Sr}$ dissolution, leading to relatively high dissolution of both $\mathrm{Sr}$ and Ir [94].

As a substitution of the A site, the Grimaud group reported a novel protonated perovskite-like phase $\mathrm{H}_{3.6} \mathrm{IrO}_{4} \cdot 3.7 \mathrm{H}_{2} \mathrm{O}$ starting from $\mathrm{Sr}_{2} \mathrm{IrO}_{4}$ through a $\mathrm{Sr}^{2+} / \mathrm{H}^{+}$cation-exchange synthetic route [85]. The corresponding structural analyses suggested that this new protonated iridate contained layers of corn-sharing $\mathrm{IrO}_{6}$ octahedra with a large amount of structural water. This specific structural feature made $\mathrm{H}_{3.6} \mathrm{IrO}_{4} \cdot 3.7 \mathrm{H}_{2} \mathrm{O}$ exhibit an improved catalytic stability via reversibly exchanging protons in acid. The enhanced OER activity of $\mathrm{H}_{3.6} \mathrm{IrO}_{4} \cdot 3.7 \mathrm{H}_{2} \mathrm{O}$ was explained by the corner-sharing $\mathrm{IrO}_{6}$ octahedral network together with the structural water in its structure. In addition, the authors also pointed out that an irreversible loss of structural water for this structure during OER, and the oxidation state of the iridate was modified with a change in the oxidation potential [85].

\subsection{Pyrochlore-type iridium-based catalysts}

Pyrochlore oxides with a general formula of $\mathrm{A}_{2} \mathrm{~B}_{2} \mathrm{O}_{7-\delta}$ are another kind of promising complex oxides with high stability and sufficient conductivity (Table 1). The earliest evaluation of the OER performance of pyrochlores was traced back to Goodenough's work in 1990 [96]. Fig. 10(a) presents a common structure of pyrochlore, which exhibits a cubic structure in a space group of Fd-3m. Generally, the large A cations occupy the $16 \mathrm{~d}$ site $(0.5,0.5,0.5)$ and connect eight $\mathrm{O}$ anions in the scalenohedron mode, which contains two 0 atoms at short distances and six $\mathrm{O}$ atoms at longer distances. The small $\mathrm{B}$ cations reside in the $16 \mathrm{c}$ site $(0,0,0)$ and coordinate with six 0 atoms to form corner-shared $\mathrm{BO}_{6}$ octahedra. $\mathrm{A}$ is $\mathrm{Bi}, \mathrm{Pb}$, alkaline earth metal (Ae), or rare earth metal (Ln) in pyrochlores, and B could be $\mathrm{Ir}, \mathrm{Ru}, \mathrm{Os}, \mathrm{Ti}, \mathrm{Sn}$, or $\mathrm{Nb}$. B sites in $\mathrm{A}_{2} \mathrm{~B}_{2} \mathrm{O}_{7-\delta}$ generally serve as catalytic active sites for the OER, and $A$ sites in the structure can alter the electronic properties of $\mathrm{B}$ sites and thereby regulate their catalytic performance [97-103].

For example, Sun et al. [98] compared two metal pyro- chlores, $\mathrm{Bi}_{2} \mathrm{Ir}_{2} \mathrm{O}_{7}$ and $\mathrm{Pb}_{2} \mathrm{Ir}_{2} \mathrm{O}_{6.5}$, with $\mathrm{IrO}_{2}$ for acidic OER. They found that their specific activity trend followed: $\mathrm{Pb}_{2} \mathrm{Ir}_{2} \mathrm{O}_{6.5}>$ $\mathrm{IrO}_{2}>\mathrm{Bi}_{2} \mathrm{Ir}_{2} \mathrm{O}_{7}$, and this activity trend could be correlated with the distortion degree of the $\mathrm{IrO}_{6}$ octahedra. The valence band spectra revealed that distorted $\mathrm{IrO}_{6}$ in $\mathrm{Pb}_{2} \mathrm{Ir}_{2} \mathrm{O}_{6.5}$ induced the disappearance of $J=1 / 2$ subbands in the valence band (Fig. $10(\mathrm{~b})$ ), while $\mathrm{Bi}_{2} \mathrm{Ir}_{2} \mathrm{O}_{7}$ exhibited a similar electronic structure to $\mathrm{IrO}_{2}$. The DFT calculations further demonstrated that owing to the distorted $\mathrm{IrO}_{6}$ coordination, $\mathrm{Pb}_{2} \mathrm{Ir}_{2} \mathrm{O}_{6.5}$ possessed a broader Ir- $5 d$ bonding region (7.8 eV bandwidth in DOS) compared with $\mathrm{IrO}_{2}(7 \mathrm{eV})$ and $\mathrm{Bi}_{2} \mathrm{Ir}_{2} \mathrm{O}_{7}(6 \mathrm{eV})$. Obviously, the trend in the $\mathrm{d}$-band widths was in accordance with the trend in OER activity. The authors believed that the broadened Ir- $5 d$ bands in $\mathrm{Pb}_{2} \mathrm{Ir}_{2} \mathrm{O}_{6.5}$ improved the orbital overlap between $\mathrm{Ir}-5 d$ and $0-2 p$, optimized the adsorption of OER intermediates, and thus gave rise to enhanced OER activity (Fig. 10(c)).

In another example, Zeng and coworkers [99] reported a family of pyrochlore oxides, $\mathrm{R}_{2} \mathrm{Ir}_{2} \mathrm{O}_{7}(\mathrm{R}=\mathrm{Ho}, \mathrm{Tb}, \mathrm{Gd}, \mathrm{Nd}$, and $\mathrm{Pr}$ ) as acidic OER catalysts. The authors found that the intrinsic OER activity of pyrochlore oxides showed a strong dependence on the types of $\mathrm{R}$ ions. The catalytic activity increased with an increase in the $\mathrm{R}$ ionic radius, and $\mathrm{Pr}_{2} \mathrm{Ir}_{2} \mathrm{O}_{7}$ exhibited the highest mass activity. The authors found that an increase in the $\mathrm{R}$ ionic radius led to an increase in the Ir-O-Ir bond angle in the pyrochlore structure and an increase in the bandwidth. Consequently, the effective electron correlations of $\mathrm{R}_{2} \mathrm{Ir}_{2} \mathrm{O}_{7}$ could be weakened by increasing the $\mathrm{R}$ ionic radius, further inducing the enhanced conductivity and enhanced covalency of Ir-O bonds (Figs. $10(\mathrm{~d}, \mathrm{e})$ ). As a result, $\mathrm{Pr}_{2} \mathrm{Ir}_{2} \mathrm{O}_{7}$ exhibited metallic behavior and strengthened hybridization between the Ir $5 d$ and $02 p$ orbitals, both of which promoted the OER reaction kinetics.

Additionally, the catalytic activities and structural stabilities of pyrochlores could also be influenced by various discrepancies such as synthetic methods, compositions, bulk thermodynamic properties, etc. The Thomas group initially used a computational approach to evaluate the phase stability, electrochemical stability, and conductivity of rare-earth pyrochlore oxides, and then synthesized these predicted materials using the spray-freeze freeze-drying approach [100]. In their work, $\mathrm{Yb}_{2} \mathrm{Ir}_{2} \mathrm{O}_{7}$ and the ruthenium series $\left(\mathrm{Gd}_{2} \mathrm{Ru}_{2} \mathrm{O}_{7}\right.$ and $\left.\mathrm{Nd}_{2} \mathrm{Ru}_{2} \mathrm{O}_{7}\right)$ displayed superior catalytic activities, while $\mathrm{Gd}_{2} \mathrm{Ir}_{2} \mathrm{O}_{7}$ and $\mathrm{Nd}_{2} \mathrm{Ir}_{2} \mathrm{O}_{7}$ exhibited comparable mass activities to $\mathrm{IrO}_{2}$ (Fig. 10(f)). As for structural stability, A-site cation leaching was detected for all materials, and B-site dissolution mainly occurred for materials containing $\mathrm{Ru}$ and $\mathrm{Nd}$. The obvious dissolution of Nd-based pyrochlores was due to the structural metastability, and the instability of Ru-based pyrochlores originated from the unstable nature of the Ru species.

\section{Conclusions and outlook}

In conclusion, PEM water electrolyzers, as a promising water electrolysis technique, can be effectively integrated with renewable energy to construct future carbon-free energy cycles. Under the brilliant blueprint and corresponding growing demand of PEM water electrolyzers, a proportionately increased requirement for noble-metal catalysts, especially irid- 
ium-based OER catalysts, substantially restricts the scale-up progress of PEM water electrolyzers. In this review, we have summarized recent research advances in iridium-containing OER catalysts and our understanding of the relationship between the microstructure and catalytic properties. We first discuss two catalytic mechanisms involved in OER (i.e., AEM and LOM) for Ir-based catalysts, and review general methods to evaluate the catalytic performance for OER. We then present some recent insights into the structural evolution of $\mathrm{IrO}_{2}$ and its relatives under OER electrocatalysis. Finally, we review three important kinds of low-iridium OER electrocatalysts, including heteroatom-containing $\mathrm{IrO}_{2}\left(\mathrm{IrO}_{x}\right)$-based catalysts and perovskite- and pyrochlore-type iridium-based catalysts. From the summarized works, it can be concluded that the specific activity of Ir species can be finely tuned by regulating the electronic structures of materials, and the catalytic stability of materials can also be correlated with the specific structural features. Although many efforts have been devoted to this field, there are still several important issues that need to be solved, as illustrated in Fig. 11.

Table 1

List of structure information, measurement parameters and catalytic performances of complex iridium-based oxides.

\begin{tabular}{|c|c|c|c|c|c|c|c|}
\hline Catalyst & $\begin{array}{c}\text { Structural } \\
\text { information }\end{array}$ & $\begin{array}{l}\text { Electrolyte } \\
\text { solution }\end{array}$ & $\begin{array}{l}\text { Mass loading } \\
\left(\mathrm{mg} / \mathrm{cm}^{2}\right)\end{array}$ & $\begin{array}{c}\eta \text { at } j_{\mathrm{geo}}=10 \\
\mathrm{~mA} / \mathrm{cm}_{\mathrm{geo}^{2}}(\mathrm{mV})\end{array}$ & Specific activity & Mass fraction of dissolved ions & Ref. \\
\hline $\mathrm{IrO}_{x} / \mathrm{SrIrO}_{3}$ & $\begin{array}{l}\text { Orthorhombic } \\
\text { perovskite }\end{array}$ & $0.5 \mathrm{M} \mathrm{H}_{2} \mathrm{SO}_{4}$ & - & $\begin{array}{c}\text { 270-290 (AFM } \\
\text { normalized) }\end{array}$ & $\begin{array}{c}1.53 \mathrm{~V} \\
\sim 12 \mathrm{~mA} / \mathrm{cm}_{\mathrm{AFM}}{ }^{2}\end{array}$ & $\begin{array}{l}\text { CV @ } 30 \min (\mathrm{ICP}) \\
\mathrm{Sr}-30 \%-50 \%\end{array}$ & [79] \\
\hline $\mathrm{Ba}_{2} \mathrm{PrIrO}_{6}$ & Cubic perovskite & $0.1 \mathrm{M} \mathrm{HClO}_{4}$ & 0.95 & $\begin{array}{c}\sim 400 \\
(\sim 425 @ 1 \mathrm{~h})\end{array}$ & $\begin{array}{c}1.53 \mathrm{~V} \\
\sim 1 \mathrm{~mA} / \mathrm{cm}_{\mathrm{ECSA}}{ }^{2}\end{array}$ & $\begin{array}{c}\text { 1.55 V @ } 1 \text { h (ICP) } \\
\text { Ba-14.2\% Ir-0.8\% Pr- } 11.3 \%\end{array}$ & [82] \\
\hline $\mathrm{Pr}_{3} \mathrm{IrO}_{7}$ & Fluorite & $0.1 \mathrm{M} \mathrm{HClO}_{4}$ & 0.95 & - & $1.53 \mathrm{~V} \sim 0.1 \mathrm{~mA} / \mathrm{cm}_{\mathrm{ECSA}}{ }^{2}$ & - & [82] \\
\hline $\mathrm{SrCo}_{0.9} \mathrm{Ir}_{0.1} \mathrm{O}_{3-\delta}$ & $\begin{array}{l}\text { Orthorhombic } \\
\text { perovskite }\end{array}$ & $0.1 \mathrm{M} \mathrm{HClO}_{4}$ & 0.255 & $\sim 330$ & $\begin{array}{c}1.53 \mathrm{~V} \\
\sim 10 \mathrm{~mA} / \mathrm{cm}_{\mathrm{BET}^{2}}\end{array}$ & $\begin{array}{c}\text { 10k cycles CV (ICP) } \\
\text { Sr-64.11\% Co-67.08\% Ir-35.5\% }\end{array}$ & [83] \\
\hline Ir doped $\mathrm{SrTiO}_{3}$ & Cubic perovskite & $0.1 \mathrm{M} \mathrm{HClO}_{4}$ & 0.21 & 247 & $\begin{array}{l}1.525 \mathrm{~V} 820 \mathrm{~A} / \mathrm{g}_{\mathrm{Ir}} \\
0.125 \mathrm{~mA} / \mathrm{cm}_{\mathrm{ECSA}^{2}} \\
0.455 \mathrm{~mA} / \mathrm{cm}_{\mathrm{BET}^{2}}\end{array}$ & - & [84] \\
\hline $\begin{array}{l}\mathrm{SrZrO}_{3}-\mathrm{SrIrO}_{3} \\
\text { solid solution }\end{array}$ & $\begin{array}{l}\text { Orthorhombic } \\
\text { perovskite }\end{array}$ & $0.1 \mathrm{M} \mathrm{HClO}_{4}$ & 0.13 & 240 & $\begin{array}{c}1.53 \mathrm{~V} 1540 \mathrm{~A} / \mathrm{g}_{\mathrm{Ir}} \\
0.22 \mathrm{~mA} / \mathrm{cm}_{\mathrm{ECSA}}{ }^{2} \\
1.2 \mathrm{~mA} / \mathrm{cm}_{\mathrm{BET}^{2}} 1.35 \mathrm{~A} / \mathrm{C}\end{array}$ & $\begin{array}{c}10 \mathrm{~mA} / \mathrm{cm}_{\mathrm{geo}^{2}} @ 10 \mathrm{~h}(\mathrm{ICP}) \\
\mathrm{Sr}-12 \% \mathrm{Ir}-1 \%\end{array}$ & {$[53]$} \\
\hline $3 \mathrm{C}-\mathrm{SrIrO}_{3}$ & $\begin{array}{l}\text { Orthorhombic } \\
\text { perovskite-3C }\end{array}$ & $0.5 \mathrm{M} \mathrm{H}_{2} \mathrm{SO}_{4}$ & 0.9 & 270 & $\begin{array}{l}1.525 \mathrm{~V} \\
38 \mathrm{~A} / \mathrm{g}_{\mathrm{Ir}}\end{array}$ & $\begin{array}{c}10 \mathrm{~mA} / \mathrm{cm}_{\mathrm{geo}}{ }^{2} @ 30 \mathrm{~h}(\mathrm{ICP}) \\
\mathrm{Sr}-24 \%\end{array}$ & [87] \\
\hline $6 \mathrm{H}-\mathrm{SrIrO}_{3}$ & $\begin{array}{c}\text { Monoclinic } \\
\text { perovskite-6H }\end{array}$ & $0.5 \mathrm{M} \mathrm{H}_{2} \mathrm{SO}_{4}$ & 0.9 & 248 & $\begin{array}{l}1.525 \mathrm{~V} \\
76 \mathrm{~A} / \mathrm{g}\end{array}$ & $\begin{array}{c}10 \mathrm{~mA} / \mathrm{cm}_{\mathrm{geo}}^{2} @ 30 \mathrm{~h}(\mathrm{ICP}) \\
\mathrm{Sr}-1 \%\end{array}$ & [87] \\
\hline $\begin{array}{l}\text { Co-doped } \\
\mathrm{SrIrO}_{3}(6 \mathrm{H})\end{array}$ & $\begin{array}{c}\text { Monoclinic } \\
\text { perovskite-6H }\end{array}$ & $0.1 \mathrm{M} \mathrm{HClO}_{4}$ & 0.45 & 235 & $\begin{array}{c}1.525 \mathrm{~V} \\
286.7 \mathrm{~A} / \mathrm{g}_{\mathrm{Ir}}\end{array}$ & $\begin{array}{l}10 \mathrm{~mA} / \mathrm{cm}_{\mathrm{geo}}^{2} @ 1 \mathrm{~h}(\mathrm{ICP}) \\
\mathrm{Sr}-12 \% \text { Co- } 0.5 \% \mathrm{Ir}-0.1 \%\end{array}$ & [104] \\
\hline $\begin{array}{l}\mathrm{BaIrO}_{3} \text { polycrys- } \\
\text { talline particles }\end{array}$ & $\begin{array}{l}\text { Monoclinic } \\
\text { perovskite }\end{array}$ & $0.5 \mathrm{M} \mathrm{H}_{2} \mathrm{SO}_{4}$ & 0.5 & - & $\begin{array}{c}1.58 \mathrm{~V} 90 \mathrm{~A} / \mathrm{g}_{\text {oxide }} \\
\sim 4 \mathrm{~A} / \mathrm{F}_{\mathrm{ECSA}}\end{array}$ & $\begin{array}{c}\text { 100-cycle CV (EDS) } \\
\text { Ba-100\% }\end{array}$ & [105] \\
\hline $\mathrm{La}_{2} \mathrm{LiIrO}_{6}$ & $\begin{array}{l}\text { Monoclinic } \\
\text { perovskite }\end{array}$ & $0.1 \mathrm{M} \mathrm{H}_{2} \mathrm{SO}_{4}$ & 0.25 & $\sim 300$ & $\begin{array}{c}1.53 \mathrm{~V} \sim 40 \mathrm{~A} / \mathrm{g}_{\text {oxide }} \\
\sim 2.5 \mathrm{~mA} / \mathrm{cm}_{\mathrm{BET}^{2}}\end{array}$ & $\begin{array}{c}1.65 \text { V @ } 10 \text { min (XPS) } \\
\text { Ir-26.7\% La-94.5\% Li-100\% }\end{array}$ & [43] \\
\hline $\mathrm{Ba}_{4} \mathrm{PrIr}_{3} \mathrm{O}_{12}$ & $\begin{array}{l}\text { Monoclinic } \\
\text { perovskite-12L }\end{array}$ & $0.1 \mathrm{M} \mathrm{HClO}_{4}$ & 0.562 & 278 & $\begin{array}{l}1.55 \mathrm{~V} 145 \mathrm{~A} / \mathrm{g}_{\mathrm{Ir}} \\
2.63 \mathrm{~mA} / \mathrm{cm}_{\mathrm{ECSA}}{ }^{2}\end{array}$ & $\begin{array}{c}10 \mathrm{~mA} / \mathrm{cm}_{\text {geo }^{2}} @ 10 \mathrm{~h}(\mathrm{ICP}) \\
\mathrm{Ba}-32 \% \operatorname{Pr}-32 \% \mathrm{Ir}-1.18 \%\end{array}$ & [90] \\
\hline $\mathrm{Ba}_{3} \mathrm{TiIr}_{2} \mathrm{O}_{9}$ & $\begin{array}{l}\text { Hexagonal } \\
\text { perovskite }\end{array}$ & $0.1 \mathrm{M} \mathrm{HClO}_{4}$ & 0.281 & 275 & $\begin{array}{c}1.53 \mathrm{~V} 0.89 \mathrm{~mA} / \mathrm{cm}_{\mathrm{ECSA}}{ }^{2} \\
250 \mathrm{~A} / \mathrm{g}_{\mathrm{Ir}}\end{array}$ & $\begin{array}{c}10 \mathrm{~mA} / \mathrm{cm}_{\mathrm{geo}}^{2} @ 10 \mathrm{~h}(\mathrm{ICP}) \\
\mathrm{Ba}-2.1 \% \mathrm{Ti}-1.6 \%\end{array}$ & [91] \\
\hline $\mathrm{Sr}_{2} \mathrm{IrO}_{4}$ & $\begin{array}{l}\text { Tetragonal } \\
\text { perovskite }\end{array}$ & $0.1 \mathrm{M} \mathrm{HClO}_{4}$ & $0.08 \mathrm{mg}_{\mathrm{Ir}} / \mathrm{cm}^{2}$ & 286 & $\begin{array}{l}1.55 \mathrm{~V} 394 \mathrm{~A} / \mathrm{g}_{\mathrm{Ir}} \\
6.1 \mathrm{~mA} / \mathrm{cm}_{\mathrm{BET}^{2}}\end{array}$ & $\begin{array}{c}10 \mathrm{~mA} / \mathrm{cm}_{\mathrm{geo}^{2}} @ 6 \mathrm{~h}(\mathrm{ICP}) \\
\mathrm{Sr}-74 \% \mathrm{Ir}-4 \%\end{array}$ & {$[94]$} \\
\hline $\mathrm{Sr}_{4} \mathrm{IrO}_{6}$ & $\begin{array}{l}\text { Hexagonal } \\
\text { perovskite }\end{array}$ & $0.1 \mathrm{M} \mathrm{HClO}_{4}$ & $0.08 \mathrm{mg}_{\mathrm{Ir}} / \mathrm{cm}^{2}$ & 287 & $\begin{array}{l}1.55 \mathrm{~V} 274 \mathrm{~A} / \mathrm{g}_{\mathrm{Ir}} \\
0.7 \mathrm{~mA} / \mathrm{cm}_{\mathrm{BET}^{2}}\end{array}$ & $\begin{array}{c}10 \mathrm{~mA} / \mathrm{cm}_{\mathrm{geo}^{2}} @ 6 \mathrm{~h}(\mathrm{ICP}) \\
\mathrm{Sr}-90 \% \mathrm{Ir}-30 \%\end{array}$ & [94] \\
\hline $\mathrm{Ca}_{2} \mathrm{IrO}_{4}$ & $\begin{array}{l}\text { Hexagonal } \\
\text { perovskite }\end{array}$ & $0.1 \mathrm{M} \mathrm{HClO}_{4}$ & 0.20 & 370 & - & - & [95] \\
\hline $\mathrm{H}_{3.6} \mathrm{IrO}_{4} \cdot 3.7 \mathrm{H}_{2} \mathrm{O}$ & $\begin{array}{l}\text { Tetragonal } \\
\text { perovskite }\end{array}$ & $0.1 \mathrm{M} \mathrm{HClO}_{4}$ & 0.255 & - & $\begin{array}{c}1.53 \mathrm{~V} \\
\sim 3.5 \mathrm{~mA} / \mathrm{cm}_{\mathrm{BET}^{2}}\end{array}$ & $\begin{array}{c}1 \mathrm{~mA} / \mathrm{cm}_{\mathrm{geo}^{2}} @ 1 \mathrm{~h}(\mathrm{ICP}) \\
\mathrm{Ir}-0.08 \%\end{array}$ & [85] \\
\hline $\mathrm{Sr}_{2} \mathrm{CoIrO}_{6}$ & $\begin{array}{l}\text { Orthorhombic } \\
\text { perovskite }\end{array}$ & $0.1 \mathrm{M} \mathrm{HClO}_{4}$ & 0.255 & $\begin{array}{c}330(\mathrm{BET} \\
\text { normalized) }\end{array}$ & $\begin{array}{c}1.55 \mathrm{~V} \\
3.5 \mathrm{~mA} / \mathrm{cm}_{\mathrm{BET}^{2}}\end{array}$ & $\begin{array}{c}1 \mathrm{~mA} / \mathrm{cm}_{\text {BET }^{2}} @ 24 \text { h (ICP) } \\
\text { Sr-5\% Co-4\% Ir-2.8\% }\end{array}$ & [106] \\
\hline $\mathrm{Sr}_{2} \mathrm{FeIrO}_{6}$ & $\begin{array}{l}\text { Triclinic } \\
\text { perovskite }\end{array}$ & $0.1 \mathrm{M} \mathrm{HClO}_{4}$ & 0.255 & $\begin{array}{c}420 \text { (BET } \\
\text { normalized) }\end{array}$ & $\begin{array}{c}1.55 \mathrm{~V} \\
1.8 \mathrm{~mA} / \mathrm{cm}_{\text {BET }^{2}}\end{array}$ & $\begin{array}{c}1 \mathrm{~mA} / \mathrm{cm}_{\text {oxide }}{ }^{2} @ 24 \mathrm{~h} \text { (ICP) } \\
\mathrm{Sr}-7 \% \text { Fe-6\% Ir-3\% }\end{array}$ & {$[106]$} \\
\hline $\mathrm{Sr}_{2} \mathrm{Fe}_{0.5} \mathrm{Ir}_{0.5} \mathrm{O}_{4}$ & $\begin{array}{l}\text { Tetragonal } \\
\text { perovskite }\end{array}$ & $0.1 \mathrm{M} \mathrm{HClO}_{4}$ & 0.255 & $\begin{array}{c}410 \text { (BET } \\
\text { normalized) }\end{array}$ & $\begin{array}{c}1.55 \mathrm{~V} \\
2.5 \mathrm{~mA} / \mathrm{cm}_{\mathrm{BET}^{2}}\end{array}$ & $\begin{array}{c}1 \mathrm{~mA} / \mathrm{cm}_{\text {oxide }^{2}} @ 24 \mathrm{~h}(\mathrm{ICP}) \\
\mathrm{Sr}-4 \% \mathrm{Fe}-6 \% \mathrm{Ir}-8 \%\end{array}$ & [106] \\
\hline $\mathrm{Pb}_{2} \mathrm{Ir}_{2} \mathrm{O}_{6.5}$ & Cubic pyrochlore & $0.1 \mathrm{M} \mathrm{HClO}_{4}$ & 0.2 & $\sim 470$ & $1.55 \mathrm{~V} \sim 150 \mathrm{~A} / \mathrm{g}_{\mathrm{Ir}} \mathrm{cm}^{-2}$ & - & [98] \\
\hline $\mathrm{Bi}_{2} \mathrm{Ir}_{2} \mathrm{O}_{7}$ & Cubic pyrochlore & $0.1 \mathrm{M} \mathrm{HClO}_{4}$ & 0.2 & & $1.6 \mathrm{~V} \sim 30 \mathrm{~A} / \mathrm{g}_{\mathrm{Ir}} \mathrm{cm}^{-2}$ & - & [98] \\
\hline $\mathrm{Pr}_{2} \mathrm{Ir}_{2} \mathrm{O}_{7}$ & Cubic pyrochlore & $0.1 \mathrm{M} \mathrm{HClO}_{4}$ & 0.285 & $\sim 290$ & $1.53 \mathrm{~V} 424.5 \mathrm{~A} / \mathrm{g}_{\mathrm{Ir}}$ & - & [99] \\
\hline $\mathrm{K}_{x \approx 0.25} \mathrm{IrO}_{2}$ & $\begin{array}{l}\text { Monoclinic } \\
\text { hollandite }\end{array}$ & $0.1 \mathrm{M} \mathrm{HClO}_{4}$ & 0.2 & 350 & $\begin{array}{c}1.53 \mathrm{~V} \\
12.2 \mathrm{~A} / \mathrm{g}_{\mathrm{Ir}}\end{array}$ & - & [107] \\
\hline $\mathrm{CaIrO}_{3}$ & Cubic perovskite & $0.1 \mathrm{M} \mathrm{HClO}_{4}$ & 0.2 & - & $1.55 \mathrm{~V} 30 \mathrm{~A} / \mathrm{g}_{\mathrm{Ir}}$ & - & [108] \\
\hline$\beta-\mathrm{H}_{2} \mathrm{IrO}_{3}$ & Orthorhombic & $0.1 \mathrm{M} \mathrm{H}_{2} \mathrm{SO}_{4}$ & 0.5 & 345 & $1.53 \mathrm{~V} 1.0 \mathrm{~mA} / \mathrm{cm}_{\mathrm{BET}^{2}}$ & 50 h@1.55 V Ir-0.2 \% & [109] \\
\hline
\end{tabular}


a

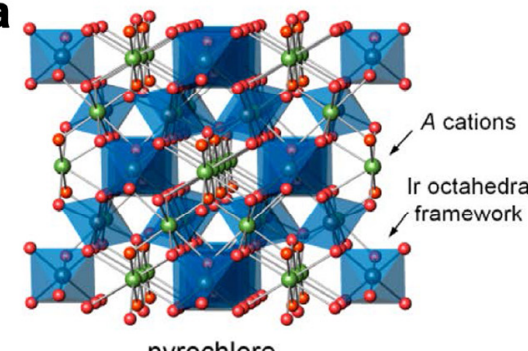

pyrochlore b

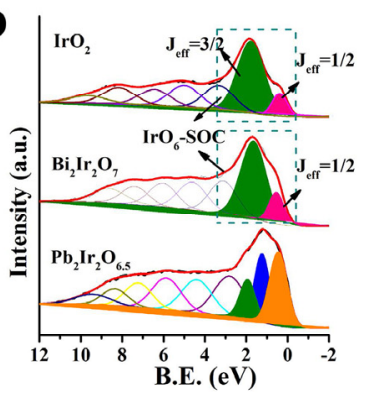

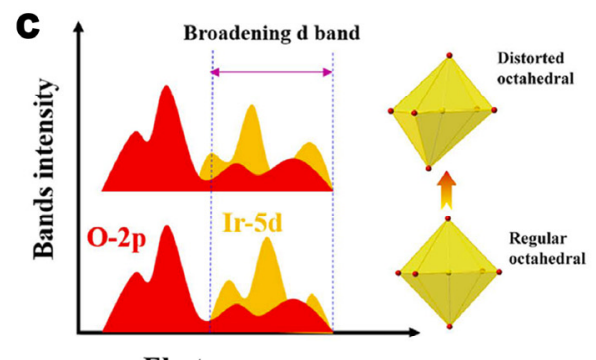

Electron energy
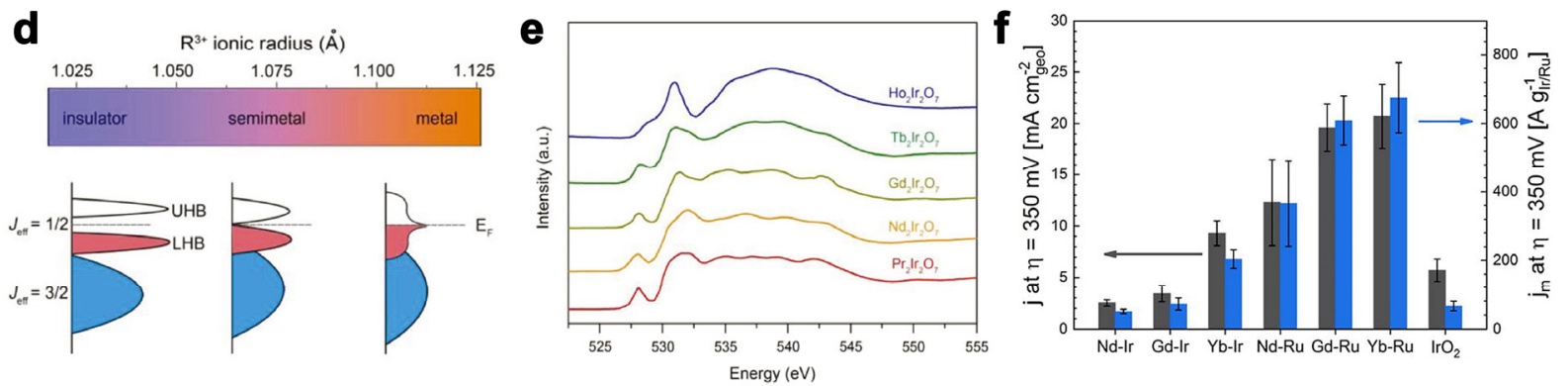

Fig. 10. (a) The crystal structure of pyrochlore. Reproduced with permission [97]. Copyright 2017, American Chemical Society. (b) Valence band spectra of $\mathrm{Pb}$-Ir, Bi-Ir pyrochlores and $\mathrm{IrO}_{2}$. (c) Schematic illustration of the broadening Ir-5d band induced by the distortion of octahedra. (b,c) Reproduced with permission [98]. Copyright 2016, Nature Publishing Group. (d) Electronic phase diagram and corresponding band structure of Ir $5 d$ orbitals. (e) 0 K-edge XAS of different pyrochlores. (d,e) Reproduced with permission [99]. Copyright 2018, Wiley-VCH. (f) Geometric current density and iridium mass activity of the different pyrochlores. Reproduced with permission [100]. Copyright 2019, American Chemical Society.

\section{(1) Specific structural design and synthesis}

According to the high correlation between the material structure and catalytic performance for acidic OER, it is undoubtedly that we can modulate the catalytic performance of one specific material by changing the structural features of the materials. Using complex iridium-based oxides as an example, the crystal structures of materials can be deconstructed into several subunits, and the geometry variations for these catalytically active ones (mainly $\mathrm{IrO}_{6}$ for iridates) including connection mode, structural distortion, bonding distances, and/or chemical valence states, together with the as-induced electronic structure changes internally influence the adsorption behaviors of the involved intermediate for OER. In addition, for catalytically inactive species in the structure, the corresponding element types, atomic radius, and/or mass fraction can also affect the structural features of materials, further leading to different catalytic performances, which suggest irreplaceable roles for all subunits. However, the general structure-activity relationships for acidic OER are not clear enough. It is necessary to combine theoretical calculation analysis together with high-throughput screening methods to construct universal structural design principles, and further develop effective synthetic methods to achieve the as-predicted structural design.

(2) Investigation of OER mechanism

The development of a catalysis mechanism influences the explanation and design principle of the corresponding catalysts. As a newly developed OER mechanism, both the clarity and acceptance of LOM are much lower than those of AEM. Thus, although both AEM and LOM are verified to be involved in OER in some cases, most studies generally limited their scope under the framework of AEM. It is important to determine the possible tendency of LOM involvement for specific catalysts, and the participation of LOM during OER may serve as an internal factor that influences the catalytic activity and structural stability of the material. As for the Ir-containing catalyst, there is also another reasonable possibility that both AEM and LOM may occur on one catalytic material simultaneously, considering the fact that $\mathrm{IrO}_{x}$ always forms in situ on the surface of iridium-based oxides during acidic OER. Accordingly, it is

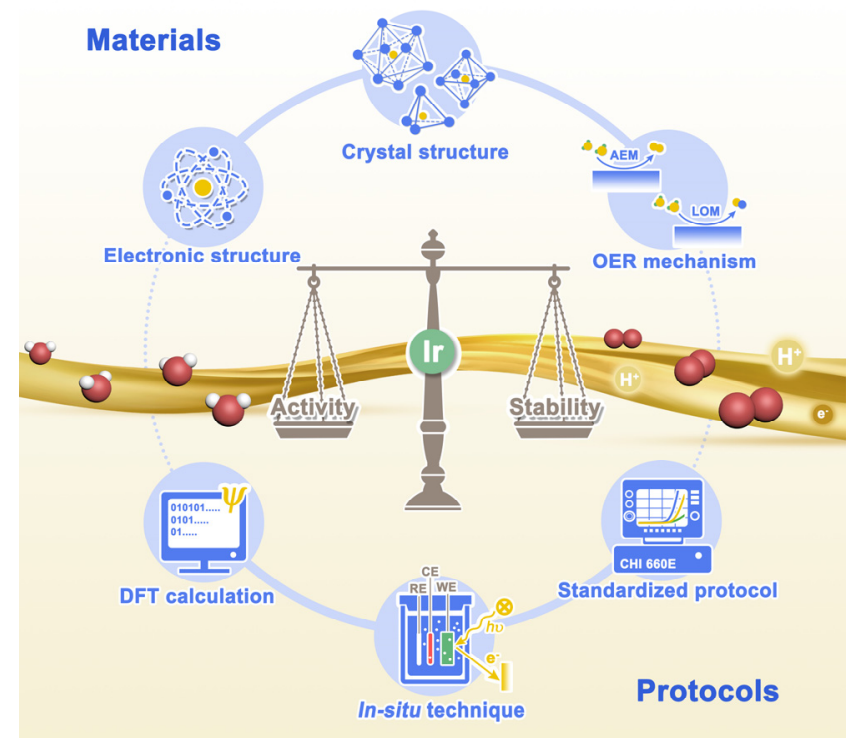

Fig. 11. Important perspectives for balancing the activity and stability of catalysts under acidic OER condition. 
necessary to find effective indicators for reflecting the possible contributions of AEM and LOM in one specified material. More comprehensive mechanistic investigations though experimental measurements and/or theoretical analyses should be conducted thoroughly for the development of both catalysis mechanisms and catalyst design.

(3) Quantitative analysis of catalytic performance

Universal quantitative analyses are the prerequisites for describing the catalytic performance of materials. Because a reversed activity-stability relationship generally exists among related catalysts for acidic OER, a catalyst with only enhanced activity does not mean that it is suitable enough for OER. Instead, the catalytic activity and catalytic stability of one specific material are equally important, and we should not focus on one feature and ignore another. Thus, it is important to construct comparable parameters for both intrinsic activity analysis and catalytic stability evaluation, in an attempt to extract the potential structure-activity relationship for as-designed catalysts. Currently, catalytic activity-related parameters with different features (as mentioned in Section 3.1) are suitable for different types of catalysts. These parameters have both advantages and disadvantages, and at the current investigation stage, it is important to perform an effective combination of these parameters to describe the intrinsic catalytic analysis of a specific material. Additionally, the evaluation metric for catalytic stability is insufficient, which means that it is currently difficult to quantitatively describe the catalytic stability features of catalysts. Therefore, obtaining a precise and integrated catalytic performance, including both the activity and stability of materials, is still a challenge at the current investigation stage for acidic OER. More parameters with simple and reproducible features need to be developed for corresponding effective quantitative analyses.

(4) Structural identification during OER

The structural variation of catalysts during OER is correlated with both the corresponding catalytic activity and catalytic stability. Specifically, the structural variations include the dissolution mechanism, valence state transition, and phase transformation of materials during OER. They may influence the involved OER catalytic mechanism internally, further leading to the similarity or diversity of catalytic performance for various catalysts. From this review, it can be concluded that the dissolution behavior of Ir-based catalysts would be influenced by synthetic conditions, chemical composition, crystal structure, and/or testing environment of materials, while the dissolution mechanism analyses for the majority of related catalysts are insufficient. Additionally, the valence state of the Ir species has been proven to undergo reversible and/or irreversible changes during the OER, but the specific valences are still ambiguous. Moreover, although the Ir sites on the surface region of Ir-based catalysts are generally considered as catalytic active sites for OER, the $\mathrm{O}$ species have also been proven to contribute significantly to the catalytic performance. The involvement of 0 active sites makes the identification of catalytic active sites rather difficult, further complicating the mechanism evaluation of the catalytic reaction. All the above unsolved issues originate from the limitations of current characterization techniques, and advanced in situ characterization measurements with high sensitivity should be developed.

(5) Effective strategies for breaking the reversed

relationship between activity and stability

Developing effective strategies to balance the catalytic activity and stability of the catalyst is the core requirement for the development of acidic OER. Based on the catalytic mechanisms involved, there might be two viable directions to enhance the activity and stability of catalysts simultaneously. (1) From the perspective of AEM, the scaling relation among various intermediates needs to be somehow broken with the aim of enhancing the intrinsic activity of catalysts. Additionally, the non-destructive adsorption mode of AEM should be maintained to keep the catalytic stability of the material. (2) Under the framework of LOM, owing to the involvement of lattice oxygen, it is important to prevent the structure of the catalyst from collapsing during the OER. Therefore, in order to retain the superior catalytic activity of LOM, the catalyst needs to tolerate the formation of surface oxygen vacancies, and the refilling adsorption rate of $\mathrm{OH}$ species must also be accelerated. Moreover, some external factors such as support passivation, catalyst detachment, and sulfate anion poisoning need to be ruled out, and a more realistic working condition for acidic OER needs to be conducted to check the catalytic performances of the materials, considering that the general measurement condition of acidic OER is not exactly the same as the working environment of commercial PEM electrolyzers.

\section{References}

[1] R. J. Detz, J. N. H. Reek, B. C. C. van der Zwaan, Energy Environ. Sci., 2018, 11, 1653-1669.

[2] S. Chu, A. Majumdar, Nature, 2012, 488, 294-303.

[3] M. Z. Jacobson, M. A. Delucchi, Energy Policy, 2011, 39, 1154-1169.

[4] M. Carmo, D. L. Fritz, J. Mergel, D. Stolten, Int. J. Hydrogen Energy, 2013, 38, 4901-4934.

[5] H. Chen, X. Liang, Y. Liu, X. Ai, T. Asefa, X. Zou, Adv. Mater., 2020, 32, 2002435.

[6] J. Chi, H. Yu, Chin. J. Catal., 2018, 39, 390-394.

[7] W. Fang, L. Huang, S. Zaman, Z. Wang, Y. Han, B. Y. Xia, Chem. Res. Chin. Univ., 2020, 36, 611-621.

[8] J. Kibsgaard, I. Chorkendorff, Nat. Energy, 2019, 4, 430-433.

[9] J. O. Bockris, Science, 1972, 176, 1323.

[10] J. A. Turner, Science, 2004, 305, 972-974.

[11] Q. Chen, Y. Nie, M. Ming, G. Fan, Y. Zhang, J.-S. Hu, Chin. J. Catal., 2020, 41, 1791-1811.

[12] W. Xu, H. Wang, Chin. J. Catal., 2017, 38, 991-1005.

[13] C. Coutanceau, S. Baranton, T. Audichon, in Hydrogen Electrochemical Production, Elsevier, 2018, 17-62.

[14] L. Gong, H. Yang, A. I. Douka, Y. Yan, B. Y. Xia, Adv. Sustain. Syst., 2020, 2000136.

[15] S. Shiva Kumar, V. Himabindu, Mater. Sci. Energy Technol., 2019, 2, 442-454.

[16] X. Sun, K. Xu, C. Fleischer, X. Liu, M. Grandcolas, R. Strandbakke, T. Bjørheim, T. Norby, A. Chatzitakis, Catalysts, 2018, 8, 657.

[17] X. Bo, K. Dastafkan, C. Zhao, ChemPhysChem, 2019, 20, 2936-2945.

[18] H. Jin, J. Joo, N. K. Chaudhari, S. Choi, K. Lee, ChemElectroChem, 2019, 6, 3244-3253. 


\section{Graphical Abstract}

Chin. J. Catal., 2021, 42: 1054-1077 doi: 10.1016/S1872-2067(20)63722-6

Iridium-containing water-oxidation catalysts in acidic electrolyte

Yipu Liu, Xiao Liang, Hui Chen, Ruiqin Gao, Lei Shi, Lan Yang,

Xiaoxin Zou*

Jilin University; NingboTech University

In an attempt to find effective strategies to balance the catalytic activities and stabilities of materials for acidic water oxidation, this review focuses on iridium-containing catalysts as examples, presenting recent representative advances in this field.

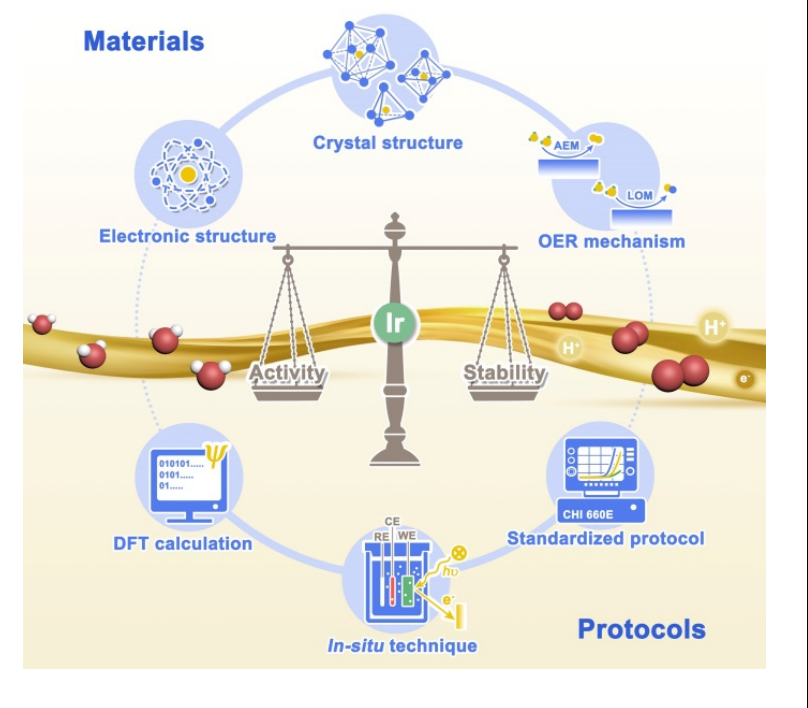

[37] Z.-F. Huang, J. Song, S. Dou, X. Li, J. Wang, X. Wang, Matter, 2019, 1, 1494-1518.

[38] J. Suntivich, K. J. May, H. A. Gasteiger, J. B. Goodenough, Y. Shao-Horn, Science, 2011, 334, 1383-1385.

[39] J. H. Montoya, A. D. Doyle, J. K. Nørskov, A. Vojvodic, Phys. Chem. Chem. Phys., 2018, 20, 3813-3818.

[40] J. Hwang, R. R. Rao, L. Giordano, Y. Katayama, Y. Yu, Y. Shao-Horn, Science, 2017, 358, 751-756.

[41] Z.-F. Huang, J. Song, Y. Du, S. Xi, S. Dou, J. M. V. Nsanzimana, C. Wang, Z. J. Xu, X. Wang, Nat. Energy, 2019, 4, 329-338.

[42] O. Kasian, S. Geiger, T. Li, J.-P. Grote, K. Schweinar, S. Zhang, C. Scheu, D. Raabe, S. Cherevko, B. Gault, K. J. J. Mayrhofer, Energy Environ. Sci., 2019, 12, 3548-3555.

[43] A. Grimaud, A. Demortière, M. Saubanère, W. Dachraoui, M. Duchamp, M.-L. Doublet, J.-M. Tarascon, Nat. Energy, 2017, 2, 16189.

[44] T. Li, O. Kasian, S. Cherevko, S. Zhang, S. Geiger, C. Scheu, P. Felfer, D. Raabe, B. Gault, K. J. J. Mayrhofer, Nat. Catal., 2018, 1, 300-305.

[45] A. Zagalskaya, V. Alexandrov, ACS Catal., 2020, 10, 3650-3657.

[46] J. S. Yoo, X. Rong, Y. Liu, A. M. Kolpak, ACS Catal., 2018, 8, 4628-4636.

[47] J. S. Yoo, Y. Liu, X. Rong, A. M. Kolpak, J. Phys. Chem. Lett., 2018, 9 , 1473-1479.

[48] C. C. L. McCrory, S. Jung, J. C. Peters, T. F. Jaramillo, J. Am. Chem. Soc., 2013, 135, 16977-16987.

[49] C. Wei, Z. J. Xu, Small Methods, 2018, 2, 1800168.

[50] N.-T. Suen, S.-F. Hung, Q. Quan, N. Zhang, Y.-J. Xu, H. M. Chen, Chem. Soc. Rev., 2017, 46, 337-365.

[51] X. Zou, Y. Zhang, Chem. Soc. Rev., 2015, 44, 5148-5180.

[52] C. Wei, S. Sun, D. Mandler, X. Wang, S. Z. Qiao, Z. J. Xu, Chem. Soc. Rev., 2019, 48, 2518-2534.

[53] X. Liang, L. Shi, R. Cao, G. Wan, W. Yan, H. Chen, Y. Liu, X. Zou, Adv. Mater., 2020, 32, 2001430.

[54] H. A. Hansen, I. C. Man, F. Studt, F. Abild-Pedersen, T. Bligaard, J. Rossmeisl, Phys. Chem. Chem. Phys., 2009, 12, 283-290.

[55] J. Park, J. Cho, Angew. Chem. Int. Ed., 2020, 59, 15314-15324. 
[56] N. Danilovic, R. Subbaraman, K.-C. Chang, S. H. Chang, Y. J. Kang, J. Snyder, A. P. Paulikas, D. Strmcnik, Y.-T. Kim, D. Myers, V. R. Stamenkovic, N. M. Markovic, J. Phys. Chem. Lett., 2014, 5, 2474-2478.

[57] J. Ruiz Esquius, D. J. Morgan, I. Spanos, D. G. Hewes, S. J. Freakley, G. J. Hutchings, ACS Appl. Energy Mater., 2020, 3, 800-809.

[58] D. Weber, L. M. Schoop, D. Wurmbrand, S. Laha, F. Podjaski, V. Duppel, K. Müller, U. Starke, B. V. Lotsch, J. Mater. Chem. A, 2018, 6, 21558-21566.

[59] W. Sun, Z. Wang, W. Q. Zaman, Z. Zhou, L. Cao, X.-Q. Gong, J. Yang, Chem. Commun., 2018, 54, 996-999.

[60] S. Geiger, O. Kasian, M. Ledendecker, E. Pizzutilo, A. M. Mingers, W. T. Fu, O. Diaz-Morales, Z. Li, T. Oellers, L. Fruchter, A. Ludwig, K. J. J. Mayrhofer, M. T. M. Koper, S. Cherevko, Nat. Catal., 2018, 1, 508-515.

[61] Y.-T. Kim, P. P. Lopes, S.-A. Park, A.-Y. Lee, J. Lim, H. Lee, S. Back, Y. Jung, N. Danilovic, V. Stamenkovic, J. Erlebacher, J. Snyder, N. M. Markovic, Nat. Commun., 2017, 8, 1449.

[62] P. Jovanovič, N. Hodnik, F. Ruiz-Zepeda, I. Arčon, B. Jozinović, M. Zorko, M. Bele, M. Šala, V. S. Šelih, S. Hočevar, M. Gaberšček, J. Am. Chem. Soc., 2017, 139, 12837-12846.

[63] O. Kasian, J.-P. Grote, S. Geiger, S. Cherevko, K. J. J. Mayrhofer, Angew. Chem. Int. Ed., 2018, 57, 2488-2491.

[64] A. Minguzzi, O. Lugaresi, E. Achilli, C. Locatelli, A. Vertova, P. Ghigna, S. Rondinini, Chem. Sci., 2014, 5, 3591-3597.

[65] A. Minguzzi, C. Locatelli, O. Lugaresi, E. Achilli, G. Cappelletti, M. Scavini, M. Coduri, P. Masala, B. Sacchi, A. Vertova, P. Ghigna, S. Rondinini, ACS Catal., 2015, 5, 5104-5115.

[66] H. G. Sanchez Casalongue, M. L. Ng, S. Kaya, D. Friebel, H. Ogasawara, A. Nilsson, Angew. Chem. Int. Ed., 2014, 53, 7169-7172.

[67] V. Pfeifer, T. E. Jones, J. J. V. Vélez, C. Massué, M. T. Greiner, R. Arrigo, D. Teschner, F. Girgsdies, M. Scherzer, J. Allan, M. Hashagen, G. Weinberg, S. Piccinin, M. Hävecker, A. Knop-Gericke, R. Schlögl, Phys. Chem. Chem. Phys., 2016, 18, 2292-2296.

[68] V. Pfeifer, T. E. Jones, S. Wrabetz, C. Massué, J. J. V. Vélez, R. Arrigo, M. Scherzer, S. Piccinin, M. Hävecker, A. Knop-Gericke, R. Schlögl, Chem. Sci., 2016, 7, 6791-6795.

[69] V. Pfeifer, T. E. Jones, J. J. V. Vélez, R. Arrigo, S. Piccinin, M. Hävecker, A. Knop-Gericke, R. Schlögl, Chem. Sci., 2017, 8, 2143-2149.

[70] V. A. Saveleva, L. Wang, D. Teschner, T. Jones, A. S. Gago, K. A. Friedrich, S. Zafeiratos, R. Schlögl, E. R. Savinova, J. Phys. Chem. Lett., 2018, 9, 3154-3160.

[71] J. Shan, C. Guo, Y. Zhu, S. Chen, L. Song, M. Jaroniec, Y. Zheng, S.-Z. Qiao, Chem, 2019, 5, 445-459.

[72] R. Kötz, S. Stucki, Electrochimica Acta, 1986, 31, 1311-1316.

[73] N. Danilovic, R. Subbaraman, K. C. Chang, S. H. Chang, Y. Kang, J. Snyder, A. P. Paulikas, D. Strmcnik, Y. T. Kim, D. Myers, V. R. Stamenkovic, N. M. Markovic, Angew. Chem. Int. Ed., 2014, 53, 14016-14021.

[74] L. Wang, V. A. Saveleva, S. Zafeiratos, E. R. Savinova, P. Lettenmeier, P. Gazdzicki, A. S. Gago, K. A. Friedrich, Nano Energy, 2017, 34, 385-391.

[75] T. Reier, Z. Pawolek, S. Cherevko, M. Bruns, T. Jones, D. Teschner, S. Selve, A. Bergmann, H. N. Nong, R. Schlögl, K. J. J. Mayrhofer, P. Strasser, J. Am. Chem. Soc., 2015, 137, 13031-13040.

[76] H. N. Nong, T. Reier, H.-S. Oh, M. Gliech, P. Paciok, T. H. T. Vu, D. Teschner, M. Heggen, V. Petkov, R. Schlögl, T. Jones, P. Strasser, Nat. Catal., 2018, 1, 841-851.

[77] J. Gao, C.-Q. Xu, S.-F. Hung, W. Liu, W. Cai, Z. Zeng, C. Jia, H. M. Chen, H. Xiao, J. Li, Y. Huang, B. Liu, J. Am. Chem. Soc., 2019, 141, 3014-3023.
[78] M. V. ten Kortenaar, J. F. Vente, D. J. W. Ijdo, S. Müller, R. Kötz, J. Power Sources, 1995, 56, 51-60.

[79] L. C. Seitz, C. F. Dickens, K. Nishio, Y. Hikita, J. Montoya, A. Doyle, C. Kirk, A. Vojvodic, H. Y. Hwang, J. K. Norskov, T. F. Jaramillo, Science, 2016, 353, 1011-1014.

[80] S. J. Moon, H. Jin, K. W. Kim, W. S. Choi, Y. S. Lee, J. Yu, G. Cao, A. Sumi, H. Funakubo, C. Bernhard, T. W. Noh, Phys. Rev. Lett., 2008, 101, 226402.

[81] J. M. Longo, J. A. Kafalas, R. J. Arnott, J. Solid State Chem., 1971, 3, 174-179.

[82] O. Diaz-Morales, S. Raaijman, R. Kortlever, P. J. Kooyman, T. Wezendonk, J. Gascon, W. T. Fu, M. T. M. Koper, Nat. Commun., 2016, 7, 12363

[83] Y. Chen, H. Li, J. Wang, Y. Du, S. Xi, Y. Sun, M. Sherburne, J. W. Ager, A. C. Fisher, Z. J. Xu, Nat. Commun., 2019, 10, 572.

[84] X. Liang, L. Shi, Y. Liu, H. Chen, R. Si, W. Yan, Q. Zhang, G. Li, L. Yang, X. Zou, Angew. Chem. Int. Ed., 2019, 58, 7631-7635.

[85] R. Zhang, P. E. Pearce, V. Pimenta, J. Cabana, H. Li, D. Alves Dalla Corte, A. M. Abakumov, G. Rousse, D. Giaume, M. Deschamps, A. Grimaud, Chem. Mater., 2020, 32, 3499-3509.

[86] H. Chen, L. Shi, X. Liang, L. Wang, T. Asefa, X. Zou, Angew. Chem. Int. Ed., 2020, 59, 19654-19658.

[87] L. Yang, G. Yu, X. Ai, W. Yan, H. Duan, W. Chen, X. Li, T. Wang, C. Zhang, X. Huang, J.-S. Chen, X. Zou, Nat. Commun., 2018, 9, 5236.

[88] Y. Lu, W. Wang, F. Xie, Mater. Res. Express, 2019, 6, 115544.

[89] R. J. D. Tilley, Perovskites: Structure-Property Relationships, John Wiley \& Sons, Ltd, Chichester, UK, 2016.

[90] R. Gao, Q. Zhang, H. Chen, X. Chu, G.-D. Li, X. Zou, J. Energy Chem., 2020, 47, 291-298.

[91] Q. Zhang, X. Liang, H. Chen, W. Yan, L. Shi, Y. Liu, J. Li, X. Zou, Chem. Mater., 2020, 32, 3904-3910.

[92] W. Feng, H. Chen, Q. Zhang, R. Gao, X. Zou, Chin. J. Catal., 2020, 41, 1692-1697.

[93] P. V. Balachandran, D. Puggioni, J. M. Rondinelli, Inorg. Chem., 2014, 53, 336-348.

[94] A. L. Strickler, D. Higgins, T. F. Jaramillo, ACS Appl. Energy Mater., 2019, 2, 5490-5498.

[95] Y. Wu, W. Sun, Z. Zhou, W. Q. Zaman, M. Tariq, L. Cao, J. Yang, ACS Omega, 2018, 3, 2902-2908.

[96] J. B. Goodenough, R. Manoharan, M. Paranthaman, J. Am. Chem. Soc., 1990, 112, 2076-2082.

[97] D. Lebedev, M. Povia, K. Waltar, P. M. Abdala, I. E. Castelli, E. Fabbri, M. V. Blanco, A. Fedorov, C. Copéret, N. Marzari, T. J. Schmidt, Chem. Mater., 2017, 29, 5182-5191.

[98] W. Sun, J.-Y. Liu, X.-Q. Gong, W.-Q. Zaman, L.-M. Cao, J. Yang, Sci. Rep., 2016, 6, 38429.

[99] C. Shang, C. Cao, D. Yu, Y. Yan, Y. Lin, H. Li, T. Zheng, X. Yan, W. Yu, S. Zhou, J. Zeng, Adv. Mater., 2019, 31, 1805104.

[100] D. F. Abbott, R. K. Pittkowski, K. Macounová, R. Nebel, E. Marelli, E. Fabbri, I. E. Castelli, P. Krtil, T. J. Schmidt, ACS Appl. Mater. Interfaces, 2019, 11, 37748-37760.

[101] P.-C. Shih, J. Kim, C.-J. Sun, H. Yang, ACS Appl. Energy Mater., 2018, 1, 3992-3998.

[102] K. Sardar, E. Petrucco, C. I. Hiley, J. D. B. Sharman, P. P. Wells, A. E. Russell, R. J. Kashtiban, J. Sloan, R. I. Walton, Angew. Chem. Int. Ed., 2014, 53, 10960-10964.

[103] K. Sardar, S. C. Ball, J. D. B. Sharman, D. Thompsett, J. M. Fisher, R. A. P. Smith, P. K. Biswas, M. R. Lees, R. J. Kashtiban, J. Sloan, R. I. Walton, Chem. Mater., 2012, 24, 4192-4200.

[104] L. Yang, H. Chen, L. Shi, X. Li, X. Chu, W. Chen, N. Li, X. Zou, ACS Appl. Mater. Interfaces, 2019, 11, 42006-42013. 
[105] C. W. Song, H. Suh, J. Bak, H. B. Bae, S.-Y. Chung, Chem, 2019, 5, 3243-3259.

[106] R. Zhang, N. Dubouis, M. Ben Osman, W. Yin, M. T. Sougrati, D. A. D. Corte, D. Giaume, A. Grimaud, Angew. Chem. Int. Ed., 2019, 58, 4571-4575.

[107] W. Sun, Y. Song, X.-Q. Gong, L. Cao, J. Yang, ACS Appl. Mater. In- terfaces, 2016, 8, 820-826.

[108] W. Sun, Z. Wang, Z. Zhou, Y. Wu, W. Q. Zaman, M. Tariq, L. Cao, X. Gong, J. Yang, Chem. Commun., 2019, 55, 5801-5804.

[109] P. E. Pearce, C. Yang, A. Iadecola, J. Rodriguez-Carvajal, G. Rousse, R. Dedryvère, A. M. Abakumov, D. Giaume, M. Deschamps, J.-M. Tarascon, A. Grimaud, Chem. Mater., 2019, 31, 5845-5855.

\title{
铱基催化剂在酸性析氧反应中的研究进展
}

\author{
刘一蒲 ${ }^{\mathrm{a}}$, 梁 宵 ${ }^{\mathrm{a}}$, 陈 辉 ${ }^{\mathrm{a}}$, 高瑞芹 ${ }^{\mathrm{a}, \mathrm{b}}$, 石 否 ${ }^{\mathrm{a}}$, 杨 岗 ${ }^{\mathrm{a}}$, 邹晓新 ${ }^{\mathrm{a}}{ }^{\mathrm{*}}$ \\ a吉林大学化学学院, 无机合成与制备化学国家重点实验室, 吉林长春130012

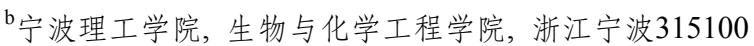

\begin{abstract}
摘要: 降低对化石能源依赖, 实现无碳能源需要构建以可再生能源(如太阳能、风能等)为主体的能源框架. 氢气是无碳能源 框架下的一种较为理想的能源载体, 而电解水制氢技术能够有效制备环境友好的高纯氢气. 其中, 质子交换膜基(PEM)电 解水技术相较碱性电解技术能够实现更高的质子导电性、电解效率、响应速度以及产物气体分离能力, 展现出较高的应用 价值. 然而, 由于PEM电解技术工作环境为高腐蚀性的强酸条件, 极大限制了催化材料的选择范围. 同时, 由于PEM电解池 的阳极端析氧反应效率远远低于阴极端析氢反应, 因此析氧反应作为瓶颈反应决定了 PEM电解池的总体工作效率. 由于 其催化条件同时具有强酸性和强氧化性, 目前只有铱基催化剂能够保持较长时间催化活性. 二氧化铱 $\left(\mathrm{IrO}_{2}\right)$ 是 PEM电解水 技术商用析氧催化剂. 然而由于铱元素在地球上储量极低 $(0.001 \mathrm{ppm})$, 因此铱基催化剂的使用严重限制了 PEM电解池的 大规模应用. 为发展PEM电解技术, 亟需研制出高活性、高稳定性的新型低铱催化剂来替代 $\mathrm{IrO}_{2}$.

本文首先总结了酸性析氧反应的催化机理, 并给出了衡量材料催化性能的普适方法. 其次, 总结了多个课题组利用 原位表征技术获得的晶化 $\mathrm{IrO}_{2}$ 以及无定形 $\mathrm{IrO}_{x}$ 在不同催化条件下的结构变化, 以期了解材料的共性催化特征及影响结构变 化的可能因素. 再次, 进一步重点描述了三类常见低铱催化剂, 包括异原子掺杂 $\mathrm{IrO}_{2}\left(\mathrm{IrO}_{x}\right)$ 基催化剂、钻钛矿型铱基催化剂 及烧绿石型铱基催化剂, 并尝试关联材料结构特征与催化本征性能. 最后, 介绍了该领域尚未解决的问题与挑战, 以期在 酸性析氧反应条件下进一步平衡催化材料的催化活性和催化稳定性.
\end{abstract}

关键词: 电催化; 析氧反应; 水裂解; 铱; 质子交换膜电解池

收稿日期: 2020-08-27. 接受日期: 2020-10-13. 上网时间: 2021-03-05.

*通讯联系人. 电话/传真: (0431)85168221; 电子信箱: xxzou@jlu.edu.cn

基金来源：国家自然科学基金(21922507，21771079，22005116，21621001); 霍英东青年教师奖励基金(161011); 博士后国际交流 计划派出项目(20190054); 111引智计划(B17020).

本文的电子版全文由Elsevier出版社在ScienceDirect上出版(http://www.sciencedirect.com/journal/chinese-journal-of-catalysis). 